\title{
Grounding zone subglacial properties from calibrated active-source seismic methods
}

\author{
Huw J. Horgan ${ }^{1}$, Laurine van Haastrecht ${ }^{1}$, Richard B. Alley ${ }^{2}$, Sridhar Anandakrishnan ${ }^{2}$, Lucas H. Beem $^{3}$, \\ Knut Christianson ${ }^{4}$, Atsuhiro Muto ${ }^{5}$, and Matthew R. Siegfried ${ }^{6}$ \\ ${ }^{1}$ Antarctic Research Centre, Victoria University of Wellington, Wellington, New Zealand \\ ${ }^{2}$ Department of Geosciences and Earth and Environmental Systems Institute, Pennsylvania State University, \\ University Park, PA 16802, USA \\ ${ }^{3}$ Department of Earth Sciences, Montana State University, Bozeman, MT 59717, USA \\ ${ }^{4}$ Earth and Space Sciences, University of Washington, Seattle, WA 98195, US \\ ${ }^{5}$ Department of Earth and Environmental Science, Temple University, Philadelphia, PA 19122, USA \\ ${ }^{6}$ Department of Geophysics, Colorado School of Mines, Golden, CO 80401, USA
}

Correspondence: Huw J. Horgan (huw.horgan@vuw.ac.nz)

Received: 2 June 2020 - Discussion started: 16 July 2020

Revised: 3 February 2021 - Accepted: 14 February 2021 - Published: 19 April 2021

\begin{abstract}
The grounding zone of Whillans Ice Stream, West Antarctica, exhibits an abrupt transition in basal properties from the grounded ice to the ocean cavity over distances of less than $0.5-1 \mathrm{~km}$. Active-source seismic methods reveal the downglacier-most grounded portion of the ice stream is underlain by a relatively stiff substrate (relatively high shear wave velocities of $1100 \pm 430 \mathrm{~m} \mathrm{~s}^{-1}$ ) compared to the deformable till found elsewhere beneath the ice stream. Changes in basal reflectivity in our study area cannot be explained by the stage of the tide. Several kilometres upstream of the grounding zone, layers of subglacial water are detected, as are regions that appear to be water layers but are less than the thickness resolvable by our technique. The presence of stiff subglacial sediment and thin water layers upstream of the grounding zone supports previous studies that have proposed the dewatering of sediment within the grounding zone and the trapping of subglacial water upstream of the ocean cavity. The setting enables calibration of our methodology using returns from the floating ice shelf. This allows a comparison of different techniques used to estimate the sizes of the seismic sources, a constraint essential for the accurate recovery of subglacial properties. We find a strong correlation (coefficient of determination $=0.46$ ) between our calibrated method and a commonly used multiplebounce method, but our results also highlight the incomplete
\end{abstract}

knowledge of other factors affecting the amplitude of seismic sources and reflections in the cryosphere.

\section{Introduction}

Grounding zones mark the transition from grounded to floating ice, standing sentinel over much of the contribution of glaciers and ice sheets to sea level. Within the grounding zone the location where the ice sheet ceases contact with the bed (the grounding line) is primarily determined by ice thickness, bed elevation, and the stage of the tide. In the Antarctic, tidally induced migration of the grounding line within the grounding zone varies from near zero in the case of abrupt changes in bed elevation and/or ice thickness to up to $10 \mathrm{~km}$ in the case of gently sloping ice plains (Brunt et al., 2011; Dawson and Bamber, 2020). Along with grounding line migration, tides correlate with ice velocity changes upstream and downstream of the grounding zone. Observations include daily velocity variability on Bindschadler Ice Stream (Anandakrishnan et al., 2003); twice daily stick-slip displacement on Whillans Ice Plain (Bindschadler et al., 2003; Winberry et al., 2009; Walter et al., 2011); daily and spring-neap velocity variability on the Ronne-Filchner Ice Shelf, Ross Ice Shelf, and Byrd Glacier (Rosier and Gudmundsson, 2020; Brunt et al., 2011; Marsh et al., 2013); and spring-neap tidal 
velocity variability on Rutford Ice Stream (Gudmundsson, 2007). Observed velocity variability has generally been attributed to tidal changes in the force balance interacting with the underlying till rheology (Bindschadler et al., 2003; Gudmundsson, 2007; Winberry et al., 2009). Subsequent studies have attributed Rutford Ice Stream's spring-neap velocity variability to changes in subglacial pore water pressure (Rosier et al., 2015), while on Rutford and elsewhere others have pointed to contact with ice shelf pinning points and at the grounding zone as the causes of observed velocity changes (Robel et al., 2017; Minchew et al., 2017; Rosier and Gudmundsson, 2020).

Early efforts to model tidal deflection of ice shelves primarily addressed vertical displacement and the associated development of strand cracks and basal crevassing at the grounding zone (Holdsworth, 1969, 1977). These models, termed stiff-bed fixed-grounding-line models by Sayag and Worster (2013), do not allow the grounding line to migrate, nor do they allow the underlying bed to deform. Despite inconsistencies in the retrieved elastic properties, subsequent applications of these models have successfully reproduced surface displacement (e.g. Vaughan, 1995; Schmeltz et al., 2002) with models accounting for basal crevassing (Rosier et al., 2017) and treating the ice as a viscoelastic material (Wild et al., 2017) shown to be more consistent with observations. The importance of grounding line migration for ice dynamics and the sensitivity of ice flow to tidal forcing has prompted renewed examination of the effect of tides on grounding line migration distances and subglacial conditions both within and upstream of the grounding zone. Sayag and Worster (2011) combined laboratory observations and an elastic sheet model in an analysis that allowed the grounding line to migrate over an elastic bed. Their approach was extended to the implications for subglacial water pressure (Sayag and Worster, 2013), showing pressure gradients alternating direction upstream of the grounding zone forming migrating barriers to subglacial water flow. Walker et al. (2013) used a fixed-grounding-line model with no vertical displacement at the grounding line and a viscoelastic ice sheet-shelf overlying an elastic bed. This approach resulted in alternating pressure gradients that may act to draw water from the ocean cavity at low tide and force it upstream at high tide. Tsai and Gudmundsson (2015) applied a novel elastic fracture approach to grounding line migration, which resulted in migration distances significantly different to elastic beam or hydrostatic approaches. Notably, Tsai and Gudmundsson (2015) demonstrated an asymmetry in grounding line migration whereby for a constant surface slope and a constant coastward bed slope, the grounding line migrates upstream as the tide rises from mean sea level much further than it propagates downstream when the tide falls from mean sea level. The subglacial system can also filter forcings, leading to velocity changes that occur at unexpected frequencies (e.g. Rosier et al., 2015). Robel et al. (2017) attributed such behaviour to the viscoelastic response of the ice shelf as it responds to changes in contact and buttressing at the grounding zone and pinning points. Alternatively, Warburton et al. (2020) coupled processes of upstream fluid flow beneath an elastic sheet and drainage through porous till and showed ice streams and ice shelves can respond at a range of frequencies. They also suggested ocean water may be retained in the subglacial system depending on the porosity of the till.

Grounding zones have been directly observed in only a few locations around Antarctica. Beneath Langovde Glacier in East Antarctica Sugiyama et al. (2014) reported a substrate of fine sediment with decimetre-scale dropstones, along with an incursion of sea water far beyond the previously mapped grounding line. In the ocean cavity proximal to the grounding line of Mackay Glacier, Powell et al. (1996) imaged a diverse range of glaciomarine lithologies, ranging from soft till to bedrock and dropstone boulders. Approximately $3 \mathrm{~km}$ downstream from Whillans Ice Stream's grounding zone, the WISSARD programme (Fricker et al., 2010) observed an ice shelf melt-out deposit with a mixture of soft mud and rock clasts (Scherer et al., 2015). Begeman et al. (2018) reported oceanographic and geophysical observations from the WISSARD borehole where they found a highly stratified water column with basal melt rates of less than $0.1 \mathrm{ma}^{-1}$. To further investigate the basal properties beneath Whillans Ice Stream's grounding zone, we here revisit the active-source seismic data reported by Horgan et al. (2013b) and apply and extend amplitude analysis methods previously used in studies addressing the basal boundary of glaciers and ice sheets (e.g. Anandakrishnan, 2003b; Smith, 2007; Holland and Anandakrishnan, 2009; Brisbourne et al., 2017; Zechmann et al., 2018; Muto et al., 2019). These methods require source amplitude and path effects to be estimated, which is often challenging due to variability in source and receiver coupling and strong vertical gradients in density and seismic velocity in the firn. Acquiring data over the ocean cavity allows calibration of these methods due to the presence of a known ice-water reflection interface. This allows us to use and expand on the methods of Holland and Anandakrishnan (2009) (hereafter referred to as H\&A2009). H\&A2009 reviewed activesource seismic methods for the recovery of subglacial properties, outlined best practices for reducing uncertainties, and presented new strategies for source size determination. Our application and extension of their methods enable a robust estimate of elastic properties beneath the ice at a relatively high spatial resolution. Our profile data cover approximately 50 line kilometres. The nominal horizontal resolution of our method is $240 \mathrm{~m}$ (based on the spatial footprint of a $100 \mathrm{~Hz}$ wave in a $3860 \mathrm{~m} \mathrm{~s}^{-1}$ medium at a depth of $760 \mathrm{~m}$ ), and we are able to image the top and bottom of a water layer $\geq 3.6 \mathrm{~m}$ thick $(\lambda / 4$, where $\lambda$ denotes wavelength, of a $100 \mathrm{~Hz}$ wave in a $1440 \mathrm{~m} \mathrm{~s}^{-1}$ medium). In theory, water layers down to $\lambda / 32$ $(0.45 \mathrm{~m})$ can be imaged; however amplitudes from these layers may not be representative of their elastic properties (e.g. Booth et al., 2012). To explore the relationship between the tidal stage and our results, we also present the timing and 
tidal stage of our experiment and Global Navigation Satellite System (GNSS) repeat transects along two profiles crossing the grounding zone.

\section{Data and methods}

We performed amplitude analysis of data from four transects that cross the grounding zone of Whillans Ice Stream (Fig. 1). These data were acquired in the austral summer of 2011/12. Acquisition was composed of an explosive seismic source detonated at approximately $27 \mathrm{~m}$ depth, with charge sizes of 0.4 (line 1) and 0.8 (lines 2 and 4) and $0.85 \mathrm{~kg}$ (line 3) at a nominal shot spacing of $240 \mathrm{~m}$. Each of line 3's $0.85 \mathrm{~kg}$ charges was composed of one $0.4 \mathrm{~kg}$ charge and three narrower $0.15 \mathrm{~kg}$ charges. All other charges were composed of equal-diameter $0.4 \mathrm{~kg}$ charges. The time between burial and detonation varied but always exceeded $24 \mathrm{~h}$. Geophones were buried approximately $0.5 \mathrm{~m}$ beneath the snow surface at $20 \mathrm{~m}$ spacings and consisted of alternating single-string $40 \mathrm{~Hz}$ geophones (even channels) and five-element $40 \mathrm{~Hz}$ georods (odd channels; Voigt et al., 2013). Acquisition used an asymmetric split spread with near and far shot-receiver offsets of 10 and $1430 \mathrm{~m}$. Seismic imaging and grounding zone determination at Whillans Ice Stream is presented in Horgan et al. (2013b).

Following H\&A2009, the amplitudes reflected off of the base of the ice and recorded at our geophones $\left(A_{i}\right.$, where $i$ denotes the receiver index) are related to our source amplitude $\left(A_{0}\right)$ by

$$
A_{i}=A_{0} \gamma_{i} R(\theta) e^{-\alpha s_{i}} \quad \text { (Eq. 1, H\&A2009), }
$$

where $R(\theta)$ denotes the angle-dependent $(\theta)$ reflection coefficient at the base of the ice described by the Zoeppritz equations (e.g. Aki and Richards, 1980). During travel along the path length $\left(s_{i}\right)$ from the source to the receiver, amplitudes are modified by path effects $\left(\gamma_{i}\right)$ and attenuation $(\alpha)$, all of which are discussed below. Both $A_{0}$ and $\gamma_{i}$ are amplitudes relative to a reference range (typically $d_{0}=1 \mathrm{~m}$; Holland and Anandakrishnan, 2009; Shearer, 2009).

\subsection{Seismic velocity model}

Tracing seismic ray paths between the source and receivers requires knowledge of the firn and ice column's seismic velocity. To achieve this we estimated a one-dimensional (1D) velocity model using shallow-seismic-refraction techniques. During shallow refraction surveying, a hammer source was recorded at $0.5 \mathrm{~m}$ horizontal intervals with near and far offsets of 0.5 and $579 \mathrm{~m}$. A velocity model (Fig. 2) was then calculated using first-break arrival times and the $\tau-p$ (intercept time-slowness) method (e.g. Shearer, 2009), which assumes that the velocity monotonically increases with depth. This method estimated a velocity of $3840 \mathrm{~m} \mathrm{~s}^{-1}$ at $80 \mathrm{~m}$ depth. Below this depth our velocity model consists of an extrapolation to a $V_{\mathrm{p}}$ corresponding to $-20^{\circ} \mathrm{C}\left(3860 \mathrm{~m} \mathrm{~s}^{-1}\right.$; Kohnen,
1974), which is kept constant to the ice base. Kohnen (1974) demonstrated a decrease in $V_{\mathrm{p}}$ of $2.3 \mathrm{~m} \mathrm{~s}^{-1}$ per degree Celsius decrease in temperature, so our velocity is fairly insensitive to our choice of temperature. Also implicit in our use of a $1 \mathrm{D}$ velocity model is an assumption that seismic velocity does not vary laterally within the survey area.

\subsection{Amplitude picking}

Amplitudes were picked on frequency-filtered and amplitude-scaled shot records guided by profiles stacked by common-depth-point. On every shot record we attempted to digitise the direct arrival, primary bed return, and first long-path multiple of the bed return (Fig. 3). The low impedance contrast at the ice-bed interface meant the longpath multiple could not be reliably picked in the grounded part of the profiles. Amplitude picking selected the zero crossing preceding the side lobe of the wavelet. Amplitude extraction was then performed on shot records with only bandpass filtering applied. Amplitudes were extracted within the wavelet encompassing the first side lobe, the central lobe, and the next side lobe. Within this wavelet, peak positive, peak negative, and root-mean-squared (rms) amplitudes were extracted. We avoided picking bed returns where direct arrival energy interferes with the bed wavelet. Our data are from ice thicknesses of approximately 730-790 m, and direct arrivals interfere with the reflection from the base of the ice beyond offsets of approximately $700 \mathrm{~m}$. While the channels with five-element georods showed better signalto-noise ratios for imaging, we here present an analysis of the single-string geophones as their amplitudes exhibit less channel-to-channel variability, the cause of which we attribute to more variability in coupling when burying the georods. Our analysis also uses the rms amplitudes, with the positive and negative peaks used to define polarity. We tested the use of peak amplitudes and fixed-wavelet-length approaches and found both resulted in a greater distribution of source sizes and less robust estimates of basal reflectivity.

\subsection{Path effects}

Path effects $\left(\gamma_{i}\right)$ modify the source amplitude during its propagation to the receiver. We calculated the total path effects as

$\gamma_{i}=\frac{\cos \theta_{i}}{s_{i}} \sqrt{\frac{z_{0}}{z_{1}}}$,

where $\theta_{i}$ denotes the angle between the incoming ray and normal incidence, $z_{0}$ and $z_{1}$ denote the acoustic impedance at the source and receiver respectively, and $s_{i}$ denotes the path length travelled between the source and receiver. Equation (2) therefore accounts for the angle at which the incoming ray arrives at the vertical-component receivers $\left(\cos \theta_{i}\right)$, amplitude scaling due to the different acoustic impedance at the source and receiver $\left(\sqrt{\frac{z_{0}}{z_{1}}}\right.$, e.g. Shearer, 2009), and geometric spreading along the ray path $\left(1 / s_{i}\right)$. We estimated 


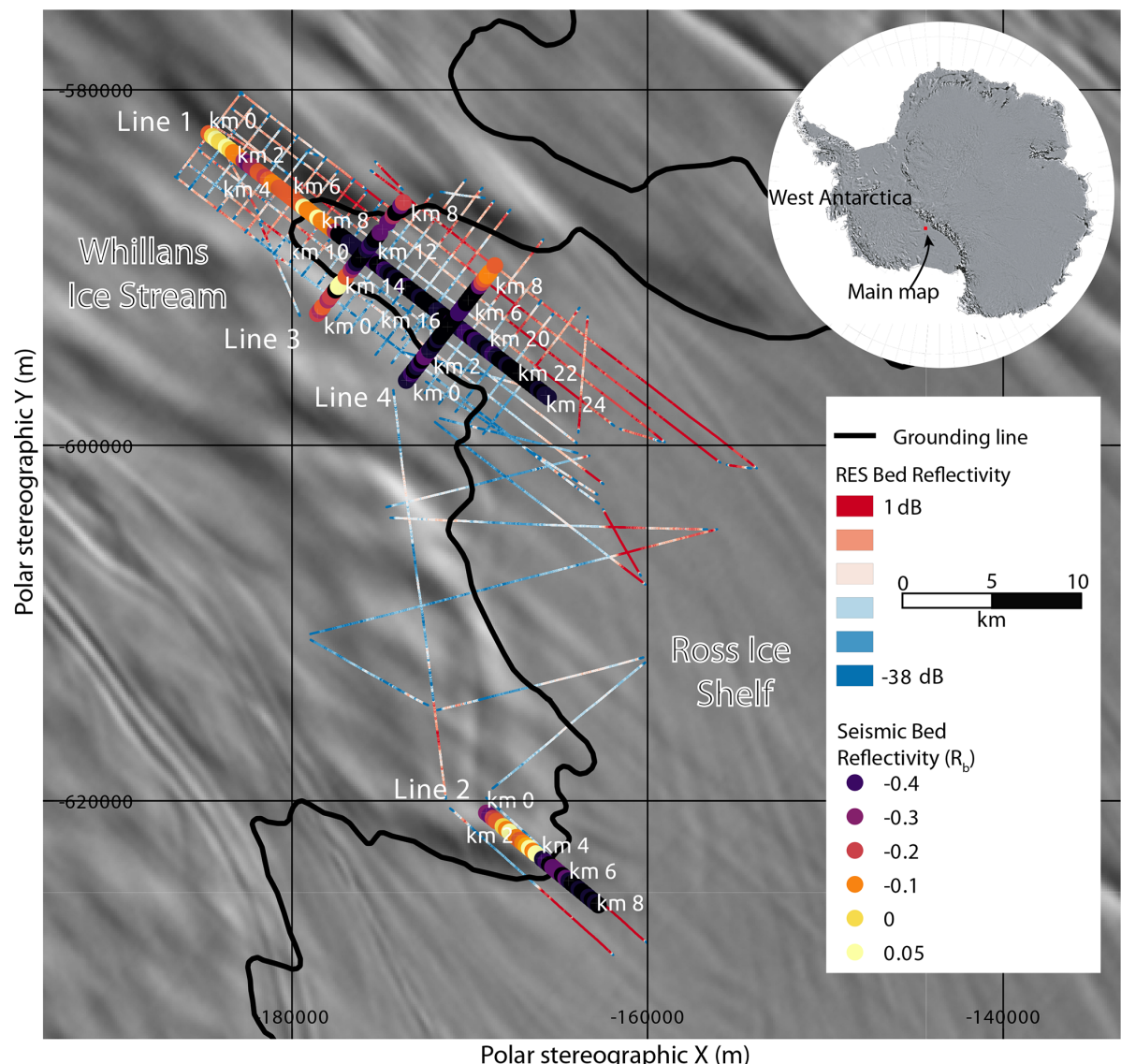

Figure 1. Location map showing the seismic profiles (lines 1-4) crossing the grounding zone of Whillans Ice Stream. Radio echo sounding (RES) basal reflectivity from Christianson et al. (2016). Seismic bed reflectivity $\left(R_{\mathrm{b}}\right)$ from this study. Background imagery from MODIS MOA (Haran et al., 2005) and grounding line from Bindschadler et al. (2011). Polar stereographic projection (metres) with a true scale at $71^{\circ}$ south.

all near-field effects using the 1D velocity model (Fig. 2) and the density-compressional-wave-velocity relationship of Kohnen and Bentley (1973). The high vertical gradients in density and velocity in polar firn lead to a $\cos \theta_{i}$ correction $\approx$ 1 , as $\theta_{i} \approx 0$, and a significant $\sqrt{\frac{z_{0}}{z_{1}}}$ correction $(\sim \sqrt{10})$ due to the different source and receiver burial depths.

H\&A2009 noted that placing receivers at a free surface results in a further doubling of recorded amplitudes for normal incidence returns. We tested including free surface amplification but did not apply it to the analysis presented here due to the burial of our receivers, although the shallow burial depth of $0.5 \mathrm{~m}$ may justify its inclusion. If included, this additional amplification would have resulted in a halving of the source sizes for two of our methods (the multiple-bounce method and the known reflector method; Sects. 2.4.1 and 2.4.3, Table 1). Including free surface amplification would have had a small effect $(<17 \%)$ on the direct-path method source size median values (Sect. 2.4.2, Table 1). Regardless of whether free surface amplification is included or excluded, our choice of preferred method for estimating $A_{0}$ would not change. The recovered bed properties also would not change as the same path effects used to calculate source size are later used to estimate bed properties.

\subsection{Source size and attenuation}

Source size $\left(A_{0}\right)$ is often estimated using the ratio of the primary bed return amplitude $\left(A_{i}\right)$ and the long-path multiple amplitude $\left(A_{\mathrm{m}, i}\right)$ (e.g. Röthlisberger, 1972; Smith, 1997; Peters et al., 2008; Brisbourne et al., 2017; Zechmann et al., 2018). This approach, termed the multiple-bounce method by H\&A2009, removes the need for an independent estimate of attenuation. However, low impedance contrast at the bed, low signal-to-noise ratios, or closely spaced subglacial reflectors, can all complicate the multiple-bounce method of determining source amplitude. Here we explore this and other methods for determining the source amplitude because moreaccurate source amplitude estimates will enable improved investigation of the basal properties resolved by seismic surveys. These methods fall into three categories: (1) multiplebounce methods, (2) direct arrival methods, and (3) known 
Table 1. Source size $\left(A_{0}\right)$ estimates.

\begin{tabular}{|c|c|c|c|c|c|c|c|c|c|c|c|c|c|}
\hline Line & $\begin{array}{r}\text { Source } \\
\text { size }(\mathrm{kg})\end{array}$ & $\begin{array}{r}A_{0 \mathrm{MB}} \\
\text { median }\end{array}$ & $\begin{array}{r}A_{0 \mathrm{MB}} \\
\text { mean }\end{array}$ & $\begin{array}{r}A_{0 \mathrm{MB}} \\
\mathrm{SD}\end{array}$ & $\begin{array}{r}A_{0 \mathrm{DP}} \\
\text { median }\end{array}$ & $\begin{array}{l}A_{0 \mathrm{DP}} \\
\text { mean }\end{array}$ & $\begin{array}{r}A_{0 D P} \\
\text { SD }\end{array}$ & $\begin{array}{r}A_{0 \mathrm{LI}} \\
\text { median }\end{array}$ & $\begin{array}{l}A_{0 \mathrm{LI}} \\
\text { mean }\end{array}$ & $\begin{array}{r}A_{0 \mathrm{LI}} \\
\mathrm{SD}\end{array}$ & $\begin{array}{r}A_{0 \mathrm{KR}} \\
\text { median }\end{array}$ & $\begin{array}{l}A_{0 \mathrm{KR}} \\
\text { mean }\end{array}$ & $\begin{array}{r}A_{0 \mathrm{KR}} \\
\mathrm{SD}\end{array}$ \\
\hline 1 & 0.40 & 1097 & 1076 & 299 & 229 & 260 & 131 & 232 & 288 & 195 & 376 & 385 & 54 \\
\hline 2 & 0.80 & 1312 & 1424 & 413 & 171 & 176 & 93 & 150 & 188 & 128 & 547 & 559 & 150 \\
\hline 3 & 0.85 & 691 & 744 & 288 & 202 & 220 & 123 & 197 & 249 & 169 & 318 & 328 & 35 \\
\hline 4 & 0.80 & 1200 & 1259 & 242 & 258 & 290 & 101 & 239 & 295 & 167 & 489 & 479 & 61 \\
\hline
\end{tabular}

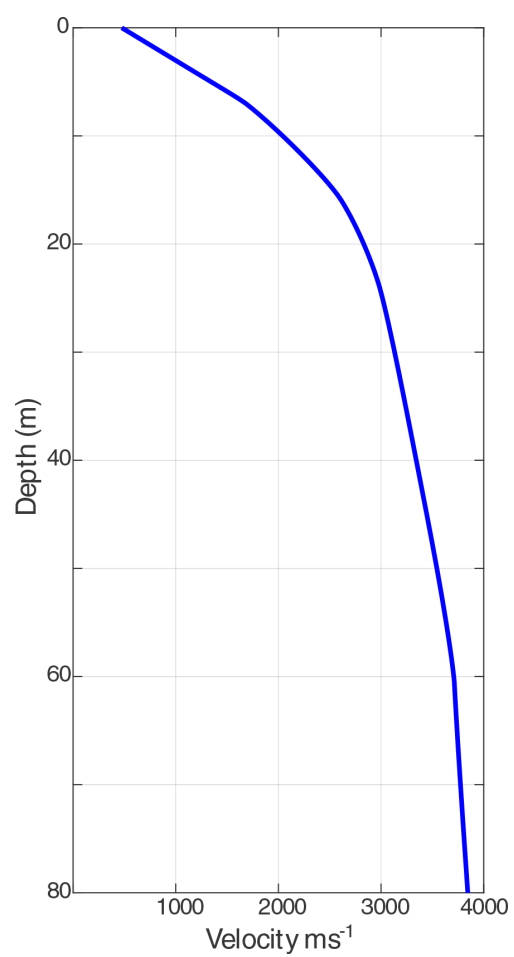

Figure 2. One-dimensional compressional wave velocity profile estimated using the $\tau-p$ method.

reflector methods. We present the results for each of the four profiles individually as three different source sizes and configurations were used.

\subsubsection{Multiple-bounce methods}

Our multiple-bounce methods used the primary-multiple amplitude ratio to estimate $A_{0}$ and followed H\&A2009. The first method requires near-normal incidence returns but does not require knowledge of attenuation $(\alpha)$ :

$A_{0, i}=\frac{A_{i}^{2}}{A_{\mathrm{m}, i}} \frac{1}{2 \gamma_{i}} \quad$ (Eq. 6, H\&A2009),

and the second method requires close-to-normal incidence returns and an estimate of attenuation:
$A_{0, i}=\frac{A_{i}^{2}}{A_{\mathrm{m}, i}} \frac{\gamma_{\mathrm{m}, i}}{\gamma_{i}^{2}} e^{\alpha\left(2 d_{i}-d_{\mathrm{m}, i}\right)} \quad$ (Eq. 7, H\&A2009),

where $d_{i}$ and $d_{\mathrm{m}, i}$ and $\gamma_{i}$ and $\gamma_{\mathrm{m}, i}$ denote the path length and path amplitude factor (Eq. 2) for the primary and multiple bed returns respectively. $A_{0}$ is then calculated as the average $A_{0, i}$ for each shot. Equations (3) and (4) give nearidentical $A_{0}$ estimates with root-mean-squared differences $\approx 0.1 \%$. Henceforth for the amplitude ratio method we report only the results from Eq. (4) with an angle cut-off of $<10^{\circ}$ and assuming an attenuation $\alpha=0.27 \mathrm{~km}^{-1}$ (following Horgan et al., 2011). This attenuation corresponds to a seismic quality factor $(Q)$ of $30-300$ for $10-100 \mathrm{~Hz}$ waves in a $3860 \mathrm{~m} \mathrm{~s}^{-1}$ medium. H\&A2009 noted that Eq. (4) is weakly dependent on uncertainties in $\alpha$. Long-path multiples from shots in which the primary reflections were from the interface between ice and seismically thick water resulted in $60,19,9$, and 24 estimates of $A_{0}$ for lines $1-4$, respectively (left column Fig. 4, $A_{0 \mathrm{MB}}$ columns Table 1).

\subsubsection{Direct-path methods}

Two methods were used to estimate source amplitude from the direct arrival amplitudes $\left(B_{i}\right)$. Direct arrivals have successfully been used to determine source size (Muto et al., 2019) and to normalise shot records (Brisbourne et al., 2017). Following H\&A2009,

$$
B_{i}=A_{0} \gamma_{\mathrm{d}, i} e^{-\alpha s_{\mathrm{d}, i}} \quad \text { (Eq. 8, H\&A2009), }
$$

where $B_{i}$ denotes direct arrival amplitude at receiver index $i$, and $s_{\mathrm{d}, i}$ and $\gamma_{\mathrm{d}, i}$ are the direct arrival path lengths and path amplitude factors. We first estimated $A_{0}$ using the direct-path pair method of H\&A2009 (H\&A2009, Eq. 9). This method uses receiver pairs where the ratio of path lengths $s_{2} / s_{1}=2$ and where the offset is sufficient that depth-averaged attenuation can be assumed the same. This negates the need for an independent attenuation estimate. Our acquisition geometry did not result in pairs where $s_{2} / s_{1}=2$ exactly, so an acceptance distance $\left(x_{1}\right)$ was set such that pairs were used if $s_{2} \geq 2 s_{1}-x_{1} \wedge s_{2} \leq 2 s_{1}+x_{1}$. We set $x_{1}=14 \mathrm{~m}$ through trial and error, looking for the minimum $x_{1}$ that resulted in multiple estimates of $A_{0}$ for all shots. This resulted in a mode of eight pairs per shot (mean of 7.7, standard deviation of 

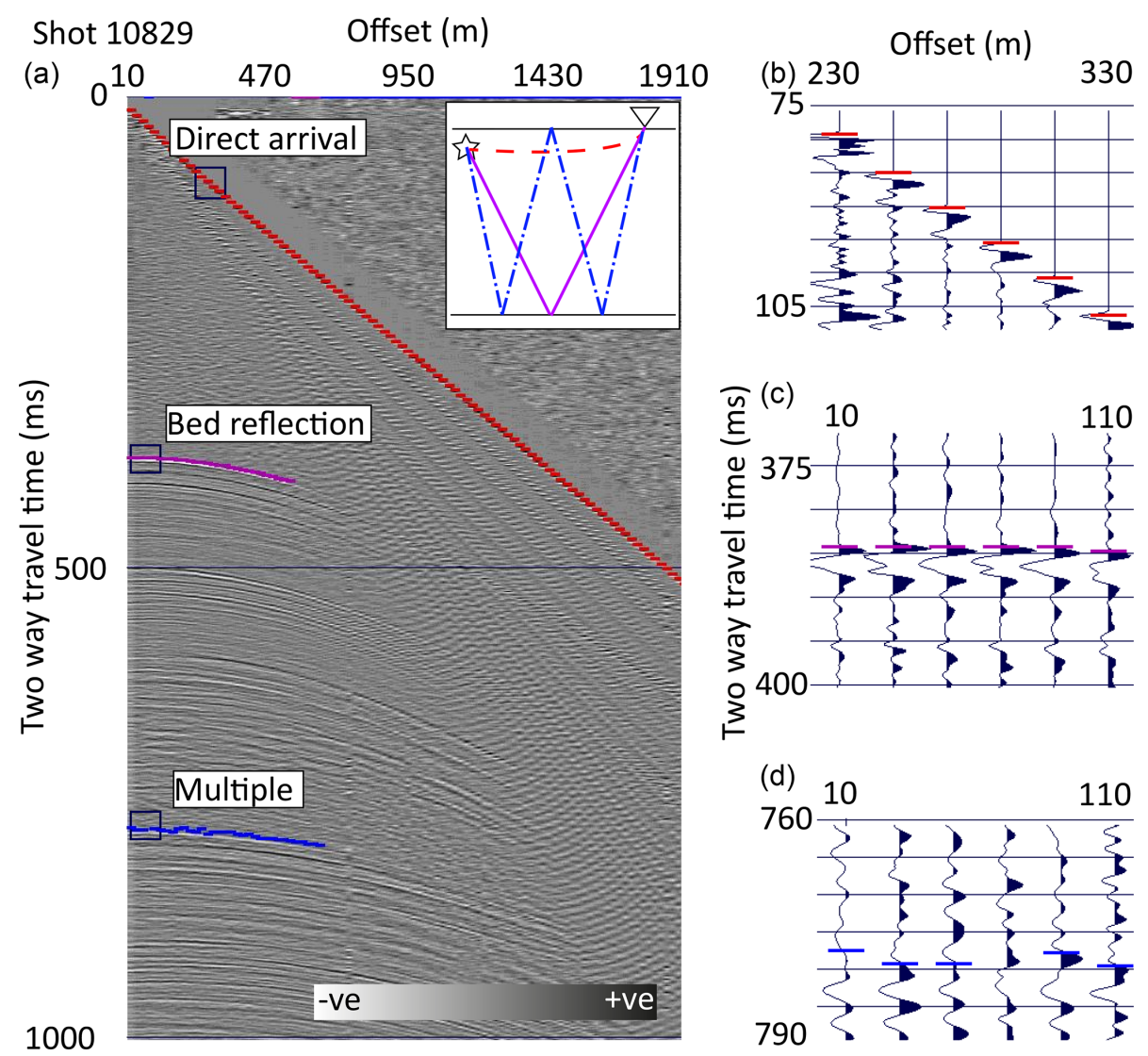

Figure 3. (a) Example shot record from floating portion of line 2 (kilometre 4.8-6.7). (a) Inset shows schematic travel paths for direct (red), primary (purple), and multiple (red) rays. Right-hand panels show wavelets and picks for the direct arrival (b), primary return (c), and multiple return $(\mathbf{d})$.

3.7). $A_{0}$ direct pair estimates are shown in Fig. 4 (centre left column) and Table 1 ( $A_{0 \mathrm{DP}}$ columns).

We also investigated $A_{0}$ estimation using all direct arrival amplitudes by fitting the observed $B_{i}$ values to Eq. (5) and minimising the misfit to determine optimal $A_{0}$ and $\alpha$ values. We refer to this method as the direct-path linear intercept method, because

$\ln \frac{B_{i}}{\gamma_{\mathrm{d}, i}}=-\alpha s_{\mathrm{d}, i}+\ln A_{0}$

shows that in $-s_{i}$ versus $\ln \frac{B i}{\gamma_{i}}$ space every shot record should exhibit a common gradient $(\alpha)$ and independent $y$ intercepts representing $\ln A_{0}$. Despite this linear form, we solved for best-fitting parameters directly from Eq. (5) using non-linear regression. We restricted our direct arrival analysis to returns from offsets greater than $450 \mathrm{~m}$, and testing up to an offset limit of $>800 \mathrm{~m}$ did not result in significantly different $A_{0}$ and $\alpha$ estimates. For both direct-path methods, path effects $\left(\gamma_{\mathrm{d}, i}\right)$ were estimated both using Eq. (2) and estimating wavefront energy using ray theory (Sect. 6.2 of Shearer, 2009, modified to account for different outgoing and incoming angles). The wavefront energy approach did not result in better
$A_{0}$ estimates, with a larger distribution and poorer correlation with the known reflector method. We therefore present results using Eq. (2), consistent with our other source size estimates. $A_{0}$ direct linear intercept estimates are shown in Fig. 4 (centre right column) and Table 1 ( $A_{0 \text { LI }}$ columns).

\subsubsection{Known reflector methods}

Reflections from a known impedance contrast, in this case the floating ice shelf overlying the ocean cavity, allow another method of determining $A_{0}$. We estimated a best-fitting $A_{0}$ for each ice shelf shot by non-linear regression of Eq. (6) (Eq. 10, H\&A2009).

$$
R(\theta)=\frac{A_{i}}{A_{0}} \frac{1}{\gamma_{i}} e^{\alpha S_{\mathrm{d}, i}} \quad \text { (Eq. 10, H\&A2009) }
$$

We determined the optimal $A_{0}$ for each floating shot by minimising the root-mean-squared misfit between the reflection amplitudes resulting from the Zoeppritz equations for the seismic properties in Table 2 and the observed bed reflection amplitudes $\left(A_{i}\right)$, Eq. (6). To account for the possibility that englacial debris may be present in the basal ice, we also optimised the seismic properties of the ice used in 
the Zoeppritz equations while keeping the underlying water properties constant. We allowed the basal ice to vary within a range encompassing debris contents of 0-20\% by volume. The range of seismic velocities for this basal ice was estimated using a Bruggeman mixing model following Röthlisberger (1972). We refer to this method as the known reflector method, and the resulting $A_{0}$ estimates are shown in Fig. 4 (right column) and Table 1 ( $A_{0 \mathrm{KR}}$ columns). The method resulted in the same number of $A_{0}$ estimates as the multiplebounce method, and each line's average basal ice properties estimated during optimisation are shown in Table 3 . The known reflector method requires an estimate of path effects but is insensitive to our assumption that $\alpha=0.27 \mathrm{~km}^{-1}$ as the same $\alpha$ used to determine $A_{0}$ is later used in Eq. (6) to determine the basal reflection coefficient. The known reflector method has similarities to the technique used by Smith et al. (2018) in their study of the lithology beneath Subglacial Lake Ellsworth, although here we explicitly estimated $A_{0}$, allowed the basal ice properties to vary, and used amplitude versus offset techniques.

\subsection{Choosing the best $A_{0}$}

The known reflector method provided our best estimate of $A_{0}$ as judged by its potential to recover accurate estimates of basal reflectivity (e.g. ice-water reflection coefficient where the ice is known to be floating) and its narrow normal distribution (Fig. 4, Table 1). The narrow distribution indicates low source size variability, consistent with a uniform firn-ice profile, a consistent drilling depth and geophone placement, back filling all shots, and allowing at least $24 \mathrm{~h}$ before detonation.

Both our direct-path methods resulted in large standard deviations (Table 1) and correlate poorly with our known reflector estimates $\left(r^{2}\right.$ (coefficient of determination) of 0.09 for the direct pair method and 0.04 for the linear intercept method, Fig. 5). The linear intercept method resulted in an average $\alpha=1.4 \pm 0.5 \mathrm{~km}^{-1}$ (mean and 1 standard deviation of the combined results for all four lines). Individual line average values range from $1.0-1.6 \mathrm{~km}^{-1}$. These $\alpha$ estimates are an order of magnitude greater than commonly used published estimates and are not used in our analysis. The multiple-bounce method correlates well with the known reflector method ( $r^{2}=0.46$, Fig. 5). Linear regression of the known reflector estimates with the multiple-bounce estimates results in a best-fitting gradient of 2.2 with an intercept of 180. However, this relationship is dependent on our estimate of $\alpha$ and our $\gamma$ estimates and will be discussed in Sect. 4.

\subsection{Estimating subglacial properties}

Using each line's $A_{0}$ values from the known reflector method (Table 1, Fig. 4 right column) we calculated the angledependent bed reflection coefficients for each shot gather $(R(\theta)$, Eq. 1). Our angle coverage typically extends up to $25^{\circ}$, with some shots extending to $30^{\circ}$. We present $R(\theta)$ as average values within $10^{\circ}$ of normal incidence $\left(R_{\mathrm{b}}\right)$ (Figs. 6a and $7 \mathrm{a}$ ) to allow comparison with normal incidence methods reported elsewhere (e.g. Muto et al., 2019). We then calculated the optimal combination of subglacial seismic velocities $\left(V_{\mathrm{p}}, V_{\mathrm{s}}\right)$ and density $(\rho)$ (Figs. 6 and $7 \mathrm{~b}-\mathrm{d}$ ) by fitting each shot's entire $R(\theta)$ to the Zoeppritz equations while imposing reasonable bounds for the subglacial material following Zechmann et al. (2018), expanded to allow for an icewater interface (Table 4). During optimisation we imposed the additional constraint that the optimal $V_{\mathrm{p}}$ and $V_{\mathrm{s}}$ must result in a realistic Poisson's ratio (v) of $0.25-0.5$ (Hamilton, 1979). Optimisation minimised the root-mean-squared misfit between the observed amplitudes for each shot and those modelled by the Zoeppritz equations using the fmincon algorithm in MATLAB ${ }^{\circledR}$. This optimisation uses a trust region approach resulting in rapid convergence. We set the basal ice's seismic properties to those obtained for each line during our $A_{0}$ known reflector method in Sect. 2.4.3 (Table 3). We repeat our $R_{\mathrm{b}}$ estimates and the optimisation of $V_{\mathrm{p}}, V_{\mathrm{s}}$, and $\rho$ values using $R(\theta)$ values estimated using all estimates of $A_{0}$ for each line, resulting in the same number of estimates of basal properties per shot as there are estimates of known reflector source size per line. In some cases our inversion repeatedly converged on the same solution, implying a misleadingly high precision. To account for this we also estimated our uncertainties by examining the retrieved basal properties from the floating portions of our survey. For all floating portions of the survey, misfit between the recovered properties and theoretical properties resulted in 1 standard deviation uncertainties for $R_{\mathrm{b}}$ of $\pm 0.09, V_{\mathrm{p}}$ of $\pm 140 \mathrm{~m} \mathrm{~s}^{-1}$, $V_{\mathrm{s}}$ of $\pm 430 \mathrm{~m} \mathrm{~s}^{-1}$, and $\rho$ of $\pm 30 \mathrm{~kg} \mathrm{~m}^{-3}$. Uncertainty estimates for each line are shown in Table 5.

\section{Results}

\subsection{Reflection coefficients and basal properties}

Line 1 exhibits generally slowly varying $R_{\mathrm{b}}$ values upstream of the grounding zone, before an abrupt change at the grounding zone (Fig. 6). This change occurs over less than $500 \mathrm{~m}$ at approximately kilometre $9 . V_{\mathrm{p}}, V_{\mathrm{s}}$, and $\rho$ values retrieved from Zoeppritz fitting exhibit a similarly abrupt change at the grounding zone. Upstream of the grounding zone binned-mode $V_{\mathrm{p}}$ and $V_{\mathrm{s}}$ values equal 2000 and $1100 \mathrm{~m} \mathrm{~s}^{-1}$ respectively, and mode $\rho$ values equal $1800 \mathrm{~kg} \mathrm{~m}^{-3}$. Kilometres 3-4 of line 1 exhibit retrieved $V_{\mathrm{s}}$ and $\rho$ values similar to those expected for water, but $R_{\mathrm{b}}$ and $V_{\mathrm{p}}$ estimates suggest otherwise. In the floating portion of the profile most retrieved properties are equal to those expected for water (Table 5). Estimates of $V_{\mathrm{s}}$ are more spatially variable with larger distributions both upstream and downstream of the grounding zone. 
Table 2. Range of seismic properties assumed for the lower ice shelf. $v$ denotes Poisson's ratio.

\begin{tabular}{lrrrr}
\hline & $V_{\mathrm{p}}\left(\mathrm{m} \mathrm{s}^{-1}\right)$ & $V_{\mathrm{s}}\left(\mathrm{m} \mathrm{s}^{-1}\right)$ & $\rho\left(\mathrm{kg} \mathrm{m}^{-3}\right)$ & $v$ \\
\hline Debris-laden ice & $3800-3870$ & $1930-2040$ & $917-1274$ & $0.297-0.330$ \\
Water & 1450 & 0 & 1028 & \\
\hline
\end{tabular}

Table 3. Seismic properties estimated in the lower ice shelf.

\begin{tabular}{rrrrrr}
\hline & $V_{\mathrm{p}}\left(\mathrm{ms}^{-1}\right)$ & $V_{\mathrm{s}}\left(\mathrm{ms}^{-1}\right)$ & $\rho\left(\mathrm{kg} \mathrm{m}^{-3}\right)$ & $v$ & $\%$ debris \\
\hline Line 1 & 3830 & 1990 & 1030 & 0.31 & 6 \\
Line 2 & 3840 & 1990 & 1030 & 0.32 & 7 \\
Line 3 & 3830 & 1990 & 1030 & 0.31 & 6 \\
Line 4 & 3850 & 1960 & 1030 & 0.33 & 6 \\
\hline
\end{tabular}

Table 4. Seismic velocity $\left(V_{\mathrm{p}}, V_{\mathrm{s}}\right)$, density $(\rho)$, and Poisson's ratio (v) bounds used for Zoeppritz fitting.

\begin{tabular}{lr}
\hline$V_{\mathrm{p}}\left(\mathrm{m} \mathrm{s}^{-1}\right)$ & $1440-2300$ \\
$V_{\mathrm{s}}\left(\mathrm{m} \mathrm{s}^{-1}\right)$ & $0-1150$ \\
$\rho\left(\mathrm{kg} \mathrm{m}^{-3}\right)$ & $1000-2500$ \\
$v$ & $0.25-0.5$ \\
\hline
\end{tabular}

Line 2 exhibits similar patterns in $R_{\mathrm{b}}$ and retrieved seismic properties to line 1 . An abrupt transition is observed at the grounding zone (kilometre 3.6), and the grounded and floating portions are dominated by distinct seismic properties (Fig. 7, left panel, Table 5). Upstream of the grounding zone two retrieved estimates exhibit properties similar to those of water (kilometre 0-0.5); however, neither are unambiguous. $V_{\mathrm{s}}$ estimates are again more variable than other parameters, with most floating shots exhibiting $V_{\mathrm{s}}$ values typical of water. Line 3 (Fig. 7, middle panel) shows both rapid and gradual changes in basal properties along the profile. Rapid changes are observed either side of kilometres 7-8 where a narrow bed feature exhibits $V_{\mathrm{p}}$ and $\rho$ estimates typical of subglacial water. Kilometres 2-4 display a gradual change in $R_{\mathrm{b}}$ while the associated transition in $V_{\mathrm{p}}$ and $\rho$ occurs abruptly over $<500 \mathrm{~m}$. $V_{\mathrm{s}}$ estimates are variable along the profile and exhibit scatter within regions thought to be both grounded (kilometres 0-3) and floating (kilometres 3.56). Line 4 (Fig. 7 , right panel) is dominated by $R_{\mathrm{b}}, V_{\mathrm{p}}$, and $\rho$ estimates typical of ice over water (kilometres $0-7$ ). The transition from these values occurs over a distance of $<1 \mathrm{~km}$ beginning at kilometre 7 . As with the other profiles the estimates of $V_{\mathrm{s}}$ are variable, but most often the floating portion of the profile (kilometres $0-7$ ) exhibits $V_{\mathrm{s}}$ estimates typical of water (Table 5).

\subsection{Experiment timing and tidal elevation}

Seismic shooting occurred at different stages of the tide, resulting in the potential for different tidal heights along pro- file. Shot and receiver elevations were not directly observed at the time of shooting, so instead we present tidal heights estimated at the floating end of the profile using Erofeeva et al. (2020) (Fig. 8). Figure 8a shows that kilometres 6-12.5 of line 1 were acquired on the falling tide when the tidal elevation varied from +0.1 to $-0.6 \mathrm{~m}$. The pronounced change in basal reflectivity that occurs at approximately kilometre 9 on line 1 (Fig. 6) does not coincide with a step in the tidal elevation. Other step changes in tidal elevation along line 1 also do not coincide with changes in basal reflectivity (e.g. kilometre 1, Fig. 6). Lines 2-4 all took less than a day to acquire and for the most part have no major step changes in tidal elevation along the profiles. An exception to this occurs on line 2 where the onset of high basal reflectivity (kilometre 3.6-4.1, Fig. 7, left panel) occurs in proximity to an offshore $0.3 \mathrm{~m}$ change in tidal elevation.

\subsection{Repeat elevation profiles across the grounding zone}

Repeat kinematic GNSS elevation profiles were acquired along lines 1 and 2 (Fig. 9) and have previously been used to validate the seismically imaged grounding line location (Horgan et al., 2013b). We locate the grounding zone using the standard deviation of elevation observations in $50 \mathrm{~m}$ spatial bins after the removal of a single best-fitting spline from each profile. Upstream of the grounding zone we expect this value to represent the method uncertainty, which comes from both the GNSS observations and our ability to repeat a track precisely, combined with a measure of the roughness of the surface. Downstream these combine with the displacement of the ice surface due to the tide. The grounding line is determined to be the point at which the standard deviation changes from values representative of grounded upstream values to those representative of floating values. The pick is subject to some interpretation as roughness and the ability to repeat a track can vary spatially and can correlate with surface slope (e.g. van der Veen et al., 2009).

Repeat elevation profiles for lines 1 and 2 were acquired on the rising tide. The tidal range for line 1 at the time we ob- 

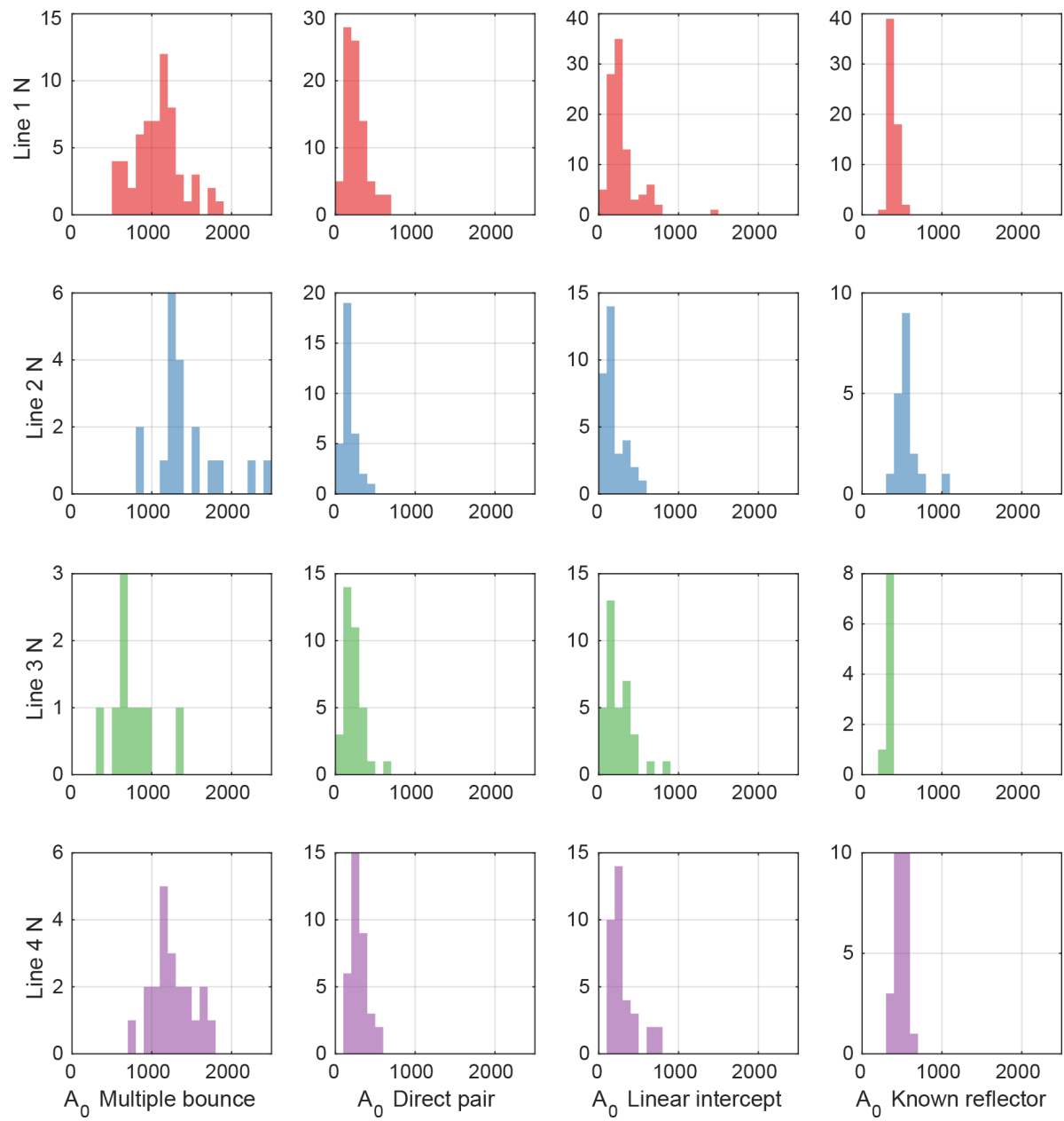

Figure 4. $A_{0}$ source size estimates for Whillans grounding zone lines $1-4$ (rows) using four methods (columns). Left column: $A_{0}$ estimates using the primary-multiple amplitude ratio method. Centre left column: $A_{0}$ direct pair estimates. Centre right column: $A_{0}$ linear intercept estimates. Right column: $A_{0}$ estimates from known reflection coefficient method assuming ice overlying water. (See Fig. 1 for line locations.)
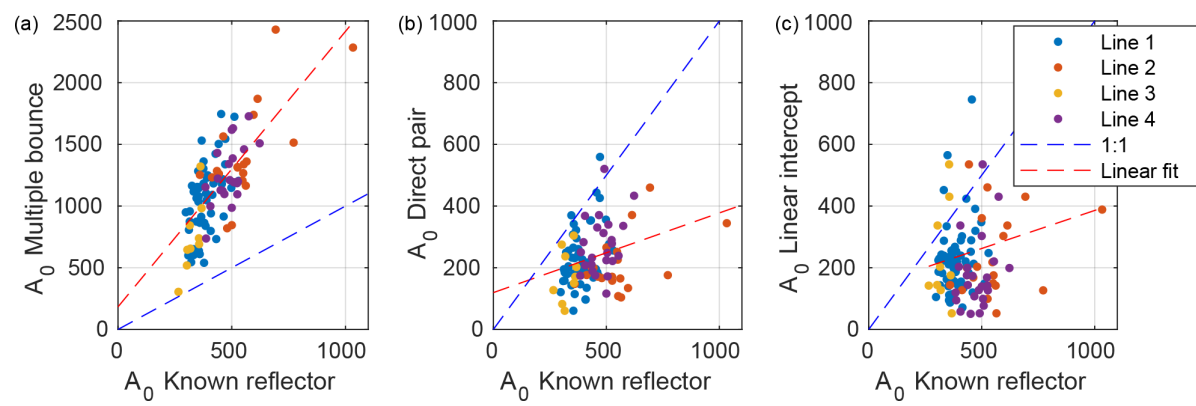

Figure 5. $A_{0}$ estimate comparisons. (a) $A_{0}$ estimates from known reflector method against $A_{0}$ estimates from multiple-bounce method (coefficient of determination $\left(r^{2}\right)$ of linear regression $\left.=0.46\right)$. (b) $A_{0}$ estimates from known reflectivity method against $A_{0}$ estimates from the direct pair method $\left(r^{2}=0.09\right)$. (c): $A_{0}$ estimates from known reflector method against $A_{0}$ estimates from linear intercept method $\left(r^{2}=0.04\right)$.

served was approximately $1.5 \mathrm{~m}$, while line 2 was observed during a range of approximately $0.35 \mathrm{~m}$. Both profiles exhibit a region of relatively high surface slope that begins upstream of the onset of vertical tidal displacement. We pick the line 1 grounding line at kilometre 9.6 and at kilometre 3.6 for line
2. Well upstream of the grounding zone, our repeat tracks typically all fall within $0.1 \mathrm{~m}$ vertically of each other. At the resolution of our data we do not observe migration of the grounding line in the GNSS data. 

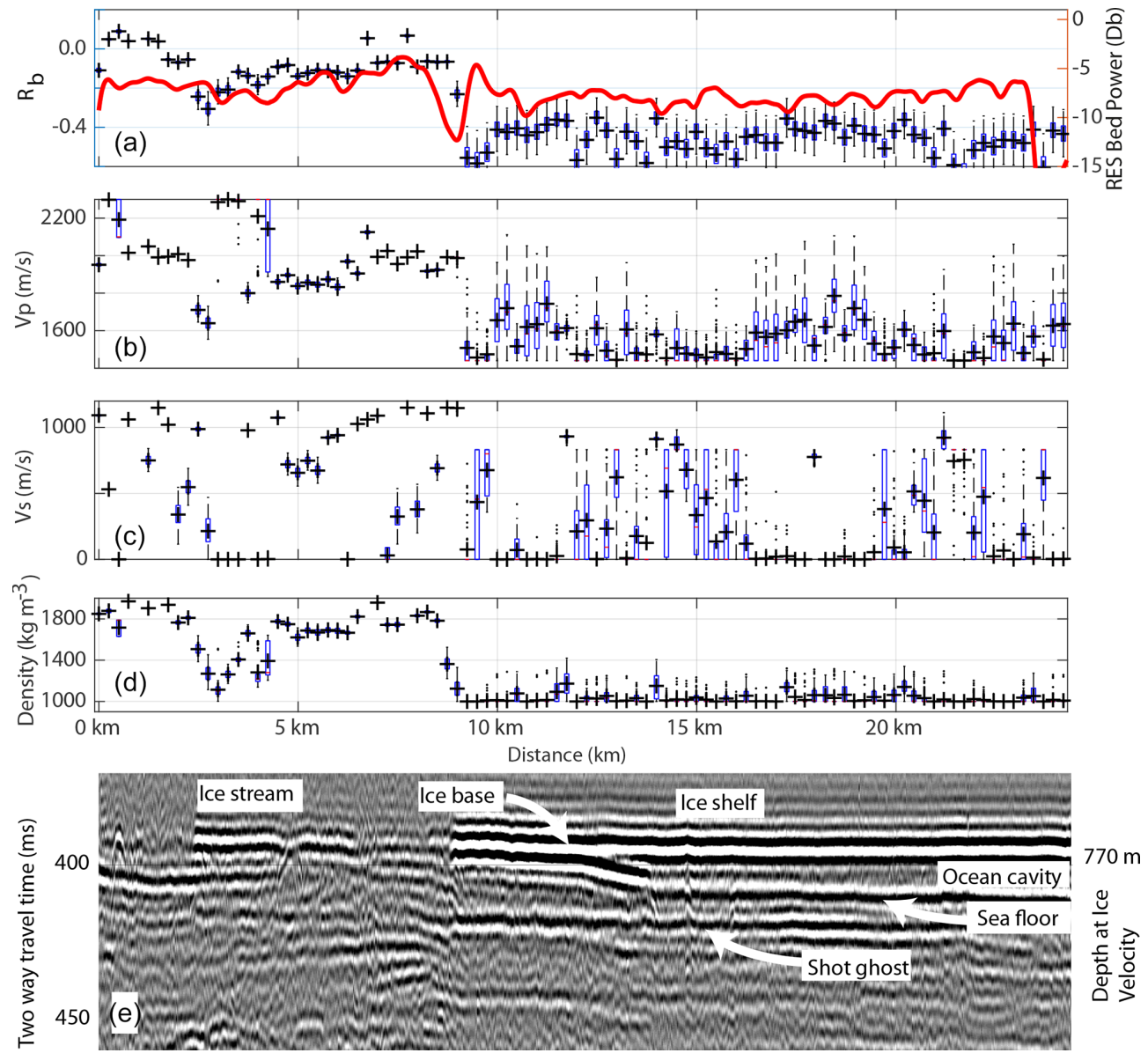

Figure 6. Line 1 (a) seismic basal reflectivity at normal incidence estimated from the average value within $10^{\circ}\left(R_{\mathrm{b}}\right)$. The red line shows radar basal reflectivity from Christianson et al. (2016). (b-d) Box plots of $V_{\mathrm{p}}, V_{\mathrm{s}}$, and $\rho$ estimated using Zoeppritz fitting and all estimated source sizes. Blue boxes show the 25 th and 75 th percentiles, whiskers extend to cover data points, and outliers are plotted as black points. Solutions using the mean source size are overlain as black crosses. All estimates use source sizes obtained using the known reflector method. (e) Stacked active-source seismic reflection profile with ice flow from left (grounded ice stream) to right (floating ice shelf). Shot ghost denotes the short-path multiple generated by the ray path from the source up to the ice-air interface then down. For profile location see Fig. 1.

Table 5. Binned-mode seismic properties estimated using normal incidence methods $\left(R_{\mathrm{b}}\right)$ and Zoeppritz fitting $\left(V_{\mathrm{p}}, V_{\mathrm{s}}\right.$, and $\left.\rho\right)$ for the grounded and floating portions of each line. Bin sizes are shown in square brackets. The 1 standard deviation uncertainties were obtained from the misfit in the floating portion of each line.

\begin{tabular}{lrrrr}
\hline & $R_{\mathrm{b}}[0.05]$ & $V_{\mathrm{p}}\left(\mathrm{m} \mathrm{s}^{-1}\right)[50]$ & $V_{\mathrm{s}}\left(\mathrm{m} \mathrm{s}^{-1}\right)[100]$ & $\rho\left(\mathrm{kg} \mathrm{m}^{3}\right)[25]$ \\
\hline Line 1 grounded & $-0.10 \pm 0.09$ & $2000 \pm 140$ & $1100 \pm 300$ & $1800 \pm 30$ \\
Line 1 floating & $-0.45 \pm 0.09$ & $1450 \pm 140$ & $0(0-300)$ & $1000 \pm 30$ \\
\hline Line 2 grounded & $-0.10 \pm 0.14$ & $2000 \pm 150$ & $1100 \pm 830$ & $1675 \pm 30$ \\
Line 2 floating & $-0.40 \pm 0.14$ & $1450 \pm 150$ & $0(0-830)$ & $1000 \pm 30$ \\
\hline Line 3 grounded & $-0.20 \pm 0.08$ & $2000 \pm 70$ & $1100 \pm 330$ & $1000 \pm 30$ \\
Line 3 floating & $-0.45 \pm 0.08$ & $1450 \pm 70$ & $0(0-330)$ & $1000 \pm 30$ \\
\hline Line 4 grounded & $-0.10 \pm 0.09$ & $2000 \pm 130$ & $1100 \pm 630$ & $2000 \pm 30$ \\
Line 4 floating & $-0.45 \pm 0.09$ & $1450 \pm 130$ & $0(0-630)$ & $1000 \pm 30$ \\
\hline
\end{tabular}



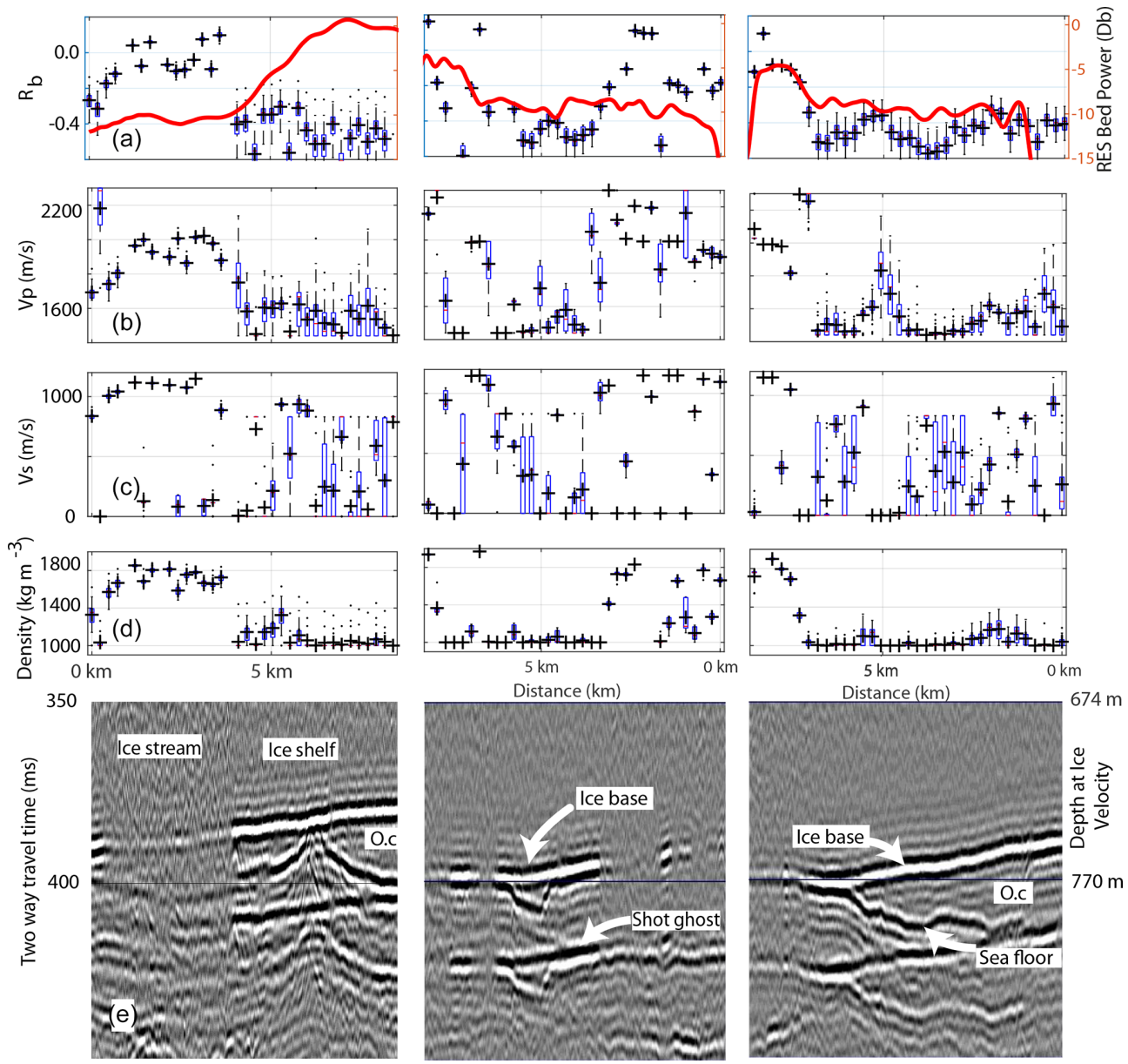

Figure 7. Lines 2 (left), 3 (middle), and 4 (right). (a) Seismic basal reflectivity at normal incidence estimated from the average value within $10^{\circ}\left(R_{\mathrm{b}}\right)$. The red line shows radar basal reflectivity from Christianson et al. (2016). (b-d) Box plots of $V_{\mathrm{p}}, V_{\mathrm{s}}$, and $\rho$ estimated using Zoeppritz fitting and all estimated source sizes. Blue boxes show the 25th and 75th percentiles, whiskers extend to cover data points, and outliers are plotted as black points. Solutions using the mean source size are overlain as black crosses. All estimates use source sizes obtained using the known reflector method. (e) Stacked active-source seismic reflection profile. Line 2 is plotted flowing from grounded (left) to floating (right). Lines 3 and 4 are plotted with flow into the page. Shot ghost denotes the short-path multiple generated by the ray path from the source to the ice-air interface and then down. O.c denotes the ocean cavity. For locations see Fig. 1.

\section{Discussion}

\subsection{Subglacial properties beneath Whillans Ice Stream's grounding zone}

Subglacial material beneath the grounded ice stream exhibits $\rho$ and $V_{\mathrm{p}}$ values in the range of dilatant till but with most $V_{\mathrm{s}}$ values typical of those observed in dewatered tills (Figs. 6 and 7, Table 5) (Zechmann et al., 2018). Our estimates of $V_{\mathrm{p}}$ and $\rho$ for all lines are close to those estimated by Luthra et al. (2016) in their active-source seismic study of a major sticky spot beneath Whillans Ice Plain. $V_{\mathrm{s}}$ estimates from the grounding zone are greater than those estimated by Luthra et al. (2016), although they overlap within uncertainties. When compared with estimates from upstream on Whillans, where Blankenship et al. (1986) measured $V_{\mathrm{s}}$ of $150 \pm 10 \mathrm{~m} \mathrm{~s}^{-1}$, our results indicate significantly stiffer till beneath the grounding zone. Basal shear stress is already known to vary spatially beneath Whillans Ice Stream. Inversion of surface elevation, ice thickness, and remotely sensed velocity observations has resolved spatially variable basal shear stress (Joughin et al., 2004b), and spatially variable rates of change of basal shear stress during the ice stream's deceleration (Beem et al., 2014). Joughin et al. (2004a) estimated low basal shear stress near the grounding zone, similar to that observed elsewhere beneath the majority of the ice plain. Lipovsky and Dunham (2017) introduced spatially variable bed properties in their rate and state friction model to better reproduce the timing and distribution of stick-slip displacement on Whillans Ice Plain. Passive seismic and geodetic observations of Whillans Ice Stream's stick-slip motion have been used to locate asperities beneath the central por- 
(a) Line 1
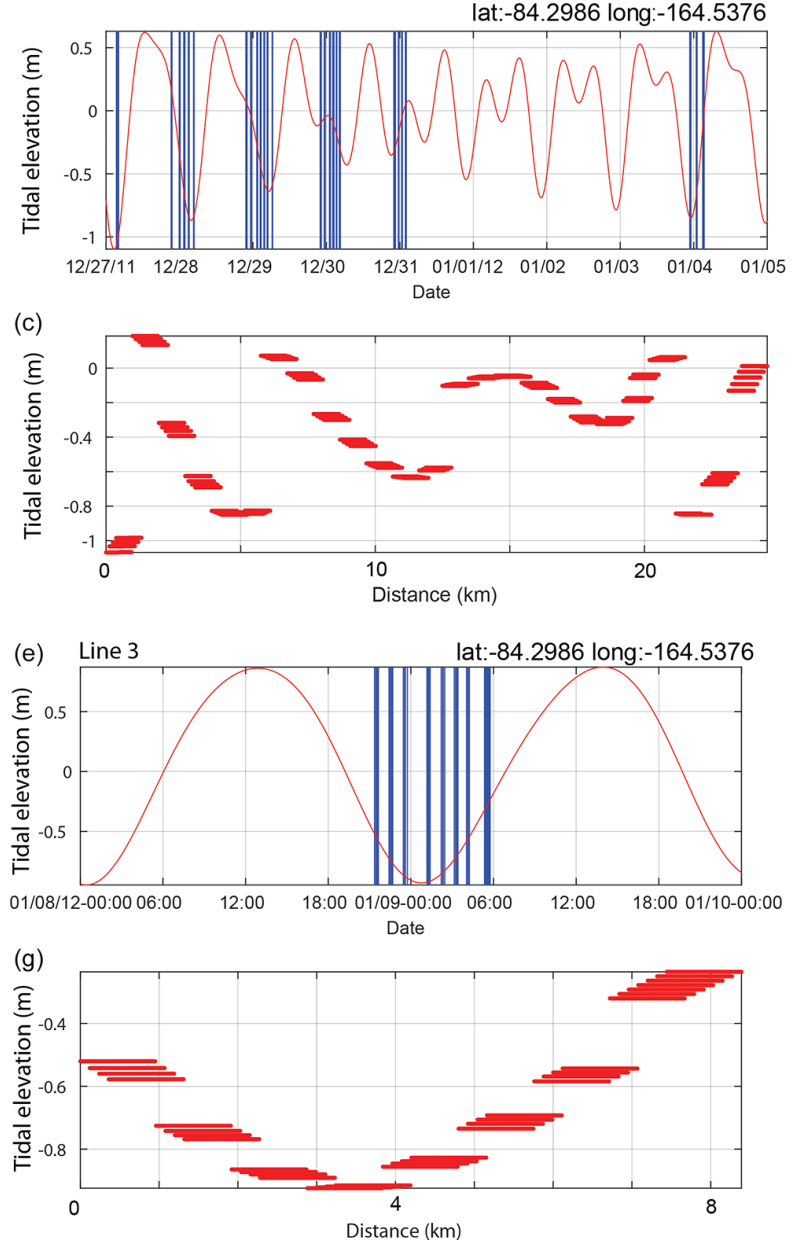

(b) Line 2
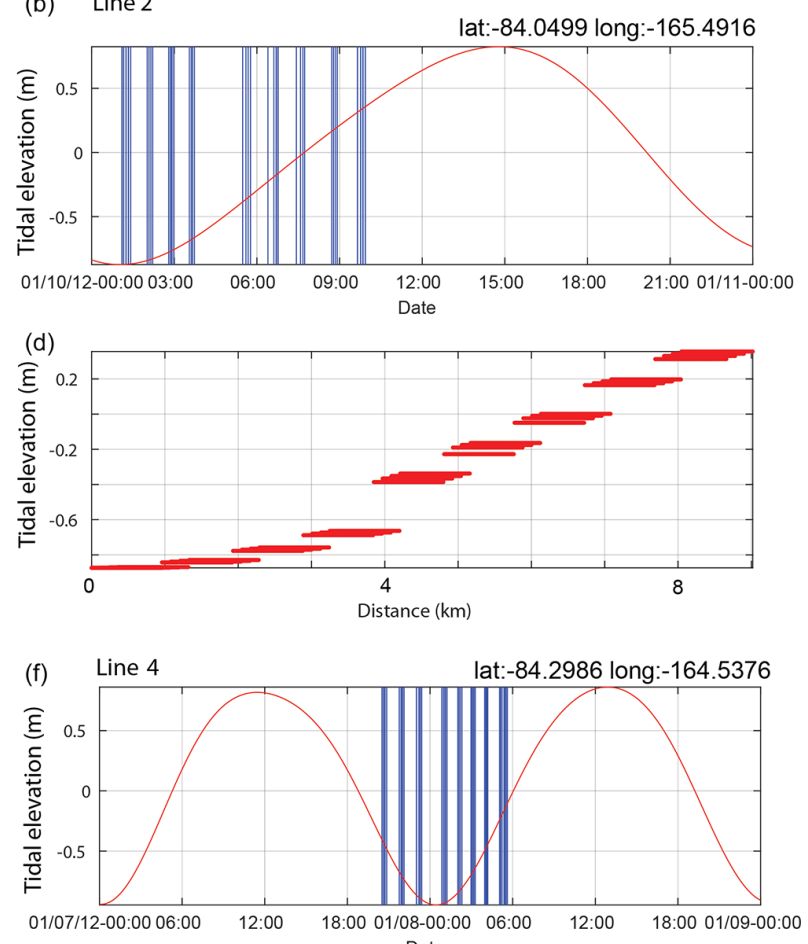

Date

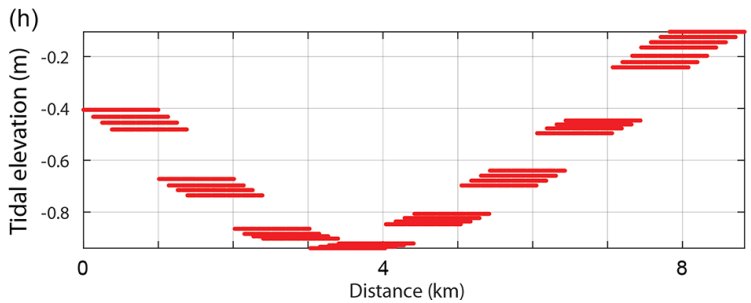

Figure 8. Shot timing and tidal elevation from Erofeeva et al. (2020). (a) Line 1. Top subplot shows the timing of shots (blue bars) overlain on the tidal elevation anomaly. Bottom subplot shows vertical tidal anomalies (Erofeeva et al., 2020) at the time of shooting as a function of distance along the profile. (b, c) Same as (a) but for lines 2, 3, and 4. Latitude (lat) and longitude (long) for each tide model time series are shown in each top subplot.

tion of the ice stream (Walter et al., 2011) and at its grounding zone (Pratt et al., 2014).

The transition in basal properties at the grounding zone of Whillans Ice Stream is abrupt in both longitudinal lines (lines 1-2), occurring over distances of less than $500 \mathrm{~m}$. This is less than the ice thickness of 730-790 m. The transverse lines (lines 3-4) exhibit less abrupt transitions but still show change over distances of less than $1 \mathrm{~km}$. The rapid transition in basal properties suggests that even in the case of a fast-flowing ice stream with low basal shear stress such as Whillans, it is necessary to solve the full Stokes equations if the ice flow velocity field is to be accurately modelled across the grounding line (Pattyn et al., 2013). The radio echo sounding (RES) results of Christianson et al. (2016) provide additional insights (Figs. 6a and 7a). Lines 1, 3, and 4, which all sample the embayment in the grounding zone to the grid north (Fig. 1), all exhibit a drop in RES basal reflectivity of approximately $3-5 \mathrm{~dB}$ as the grounding zone is crossed from the grounded ice stream to the floating ice shelf. This change occurs over similar length scales to the seismically detected transition. In contrast, line 2 , which crosses the peninsula to the grid south exhibits a gradual increase in RES basal reflectivity of approximately $10 \mathrm{~dB}$ after the ice goes afloat, over a distance of approximately $3 \mathrm{~km}$. Christianson et al. (2016) attribute the differences in the RES-detected transitions to the presence of basal roughness (fluting, modelled with a $20 \mathrm{~m}$ wavelength and $4 \mathrm{~m}$ root-mean-squared heights) and entrained debris in the ice shelf in the embayment and a basal interface that is becoming smoother and losing the basal debris zone due to basal melt at the peninsula. The percentage of entrained debris we obtained during source size estimation is similar across all four lines $(6 \%-7 \%)$, indicating differing debris content is unlikely to be the cause of the differences in RES basal reflectivity. MacGregor et al. (2011) 
(a)
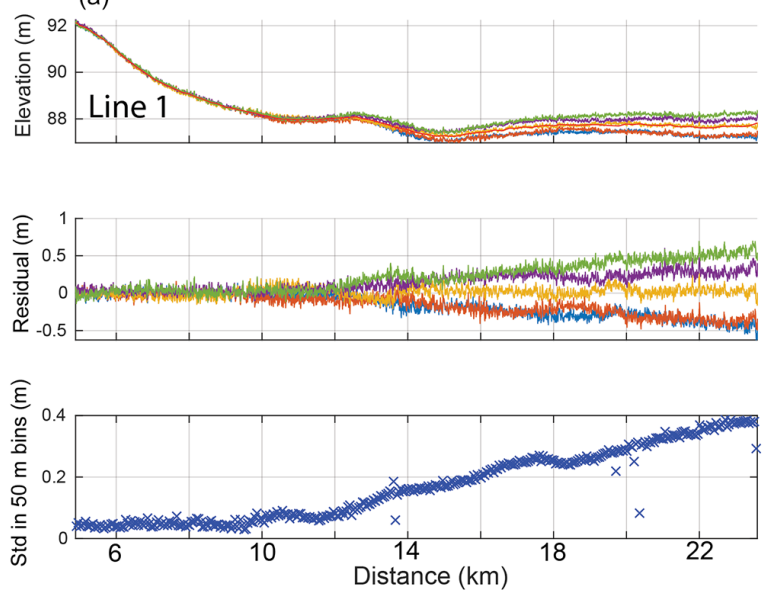

(c)
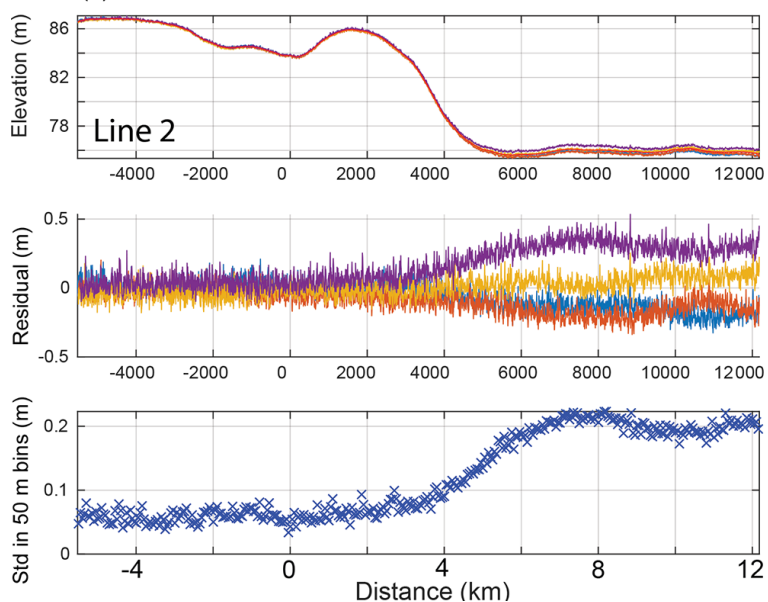

(b)

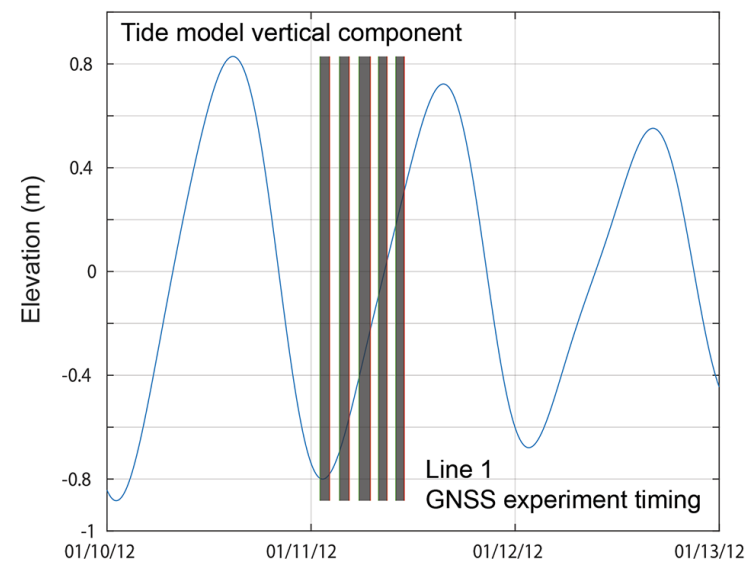

(d)

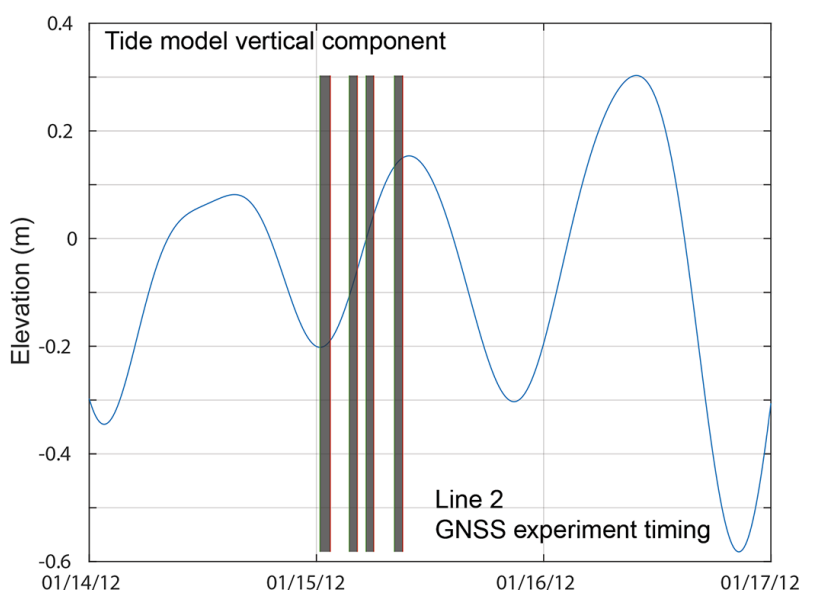

Figure 9. Repeat kinematic profiling along lines 1 (a, b) and 2 (c, d). (a and c) The elevation (top), residual elevation after removal of a best-fitting spline (middle), and standard deviation of residual elevation in $50 \mathrm{~m}$ spatial bins (bottom). (b and d) The timing of the GNSS profile data collection (vertical overlain on the vertical elevation anomaly of Erofeeva et al. (2020).

reported low-frequency (2 MHz) RES bed reflectivity from elsewhere on Whillans Ice Stream and the adjacent Kamb Ice Stream and found negligible change in RES reflectivity when crossing the grounding zone. One possibility discussed by MacGregor et al. (2011) was the presence of brackish water upstream of the grounding line, smoothing the RES-imaged transition from grounded to floating ice.

\subsection{Water upstream of the grounding zone}

Upstream of the grounding zone several regions (e.g. line 1, kilometres 3-4; line 2, kilometre 0-0.5; line 3 kilometres 78 ) exhibit properties that indicate the presence of subglacial water, although not without ambiguity. This ambiguity likely results from water column thicknesses that are less than one-quarter the dominant seismic wavelength for our data $(\lambda / 4 \approx 3.6 \mathrm{~m})$. Visual inspection of shot records shows that in these regions the thin-layer effects detailed by Booth et al.
(2012) result in constructive and destructive interference of our basal wavelet, leading to best-fitting parameter combinations that are not representative of the contrast in properties. A similar phenomenon likely results in the anomalous estimated values at the grounding zone of line 1 (Fig. 6, kilometre 9) and for kilometre 7-7.5 of line 3 (Fig. 7). However, no similar attribution is possible for the $V_{\mathrm{s}}$ outliers in the floating portions of all lines, which instead appear to correspond to low signal-to-noise ratios apparent in visual inspection of the shot records.

Our seismic methods are insensitive to whether the subglacial water is sourced from beneath the ice stream or from the ocean cavity. The WISSARD field site was initially selected as it lay on the subglacial drainage path from Subglacial Lake Whillans to the ocean cavity (Fricker et al., 2010; Carter and Fricker, 2012). Oversnow geophysical surveying, including the data presented here and in Christianson et al. (2013), has shown the potential for estuarine flow across 
the grounding zone (Horgan et al., 2013a). Shot times, tidal stage, and bed reflectivity lack correlation between changes in tidal height and imaged bed properties. One exception to this occurs on line 2 where the change in bed properties at kilometre 3.6 (Fig. 6, left column) occurs in proximity to a $0.3 \mathrm{~m}$ change in tidal height at kilometres 3.8-4.2 (Fig. 8b). We consider this correlation coincidental as line 2's grounding line position appears pinned at kilometre 3.6 by an approximately $6 \mathrm{~m}$ change in bed elevation. Also, repeat GNSS profiling (Fig. 9c) indicates vertical change at line 2's grounding line is likely to be much less than that estimated offshore, and even a $0.3 \mathrm{~m}$ change in water column thickness would be insufficient to cause the pronounced change in reflectivity observed. Line 1's repeat GNSS profiling (Fig. 9a) locates the onset of vertical tidal deflection $0.6 \mathrm{~km}$ downstream of the seismically resolved change in subglacial properties. This indicates the presence of water upstream of the of the GNSS-picked grounding line, but the subjective nature of the GNSS method makes this conclusion tentative. Line 1's repeat GNSS profiling also suggests the region between kilometres 9.6-12 is a zone of ephemeral grounding, resulting in a smaller distribution of elevations over the observed portion of the tidal cycle (Fig. 9a, bottom subplot). Our experiment was not designed to study changing bed properties over a tidal cycle, which would be better examined using tilt metres or fixed GNSS stations and a fixed geophone deployment with a source repeating at the same location.

While our methods are not able to determine the process of stiffening at the grounding zone and ponding upstream, our observations are broadly consistent with the findings of several previous modelling studies. In the nomenclature of Sayag and Worster (2013), our study location appears to be a fixed-grounding-line, stiff-bedded system, although the zone of ephemeral grounding and the $0.6 \mathrm{~km}$ difference between our seismically determined grounding zone and that located by our repeat GNSS profiling shows some grounding line migration may be occurring on line 1. Our seismic properties indicate a stiff bed over thicknesses of at least approximately $5 \mathrm{~m}\left(\lambda / 4=5 \mathrm{~m}\right.$ for a $100 \mathrm{~Hz}$ wave in a $2000 \mathrm{~m} \mathrm{~s}^{-1}$ medium). Estimated seismic velocities and densities imply Young's modulus $(E)$ of 3.1-6.2 GPa in the subglacial material with lines 1, 2, and 4 all exhibiting $E=5.2-6.2 \mathrm{GPa}$. Our observations at this location are not able to identify the asymmetric grounding line migration outlined by Tsai and Gudmundsson (2015). Local variations in bed and surface slope and ice thickness are likely to contribute to this; however the resolution of our GNSS method and our temporal sampling of basal properties also contribute to a lack of fidelity. Stiff till beneath the grounding zone and localised bodies of water upstream of the grounding zone are in keeping with the compression and dewatering of subglacial till due to ice flexure modelled by Walker et al. (2013). Stiffening of the till was also invoked by Christianson et al. (2013) as the cause of the enhanced internal deformation evident in radio echo sounding profiling across the grounding zone. The presence of isolated water bodies also aligns with the alternating pressure gradients causing barriers to water flow upstream of the grounding proposed by Sayag and Worster (2013) and the movement of water upstream of the grounding line modelled by Warburton et al. (2020). Warburton et al. (2020) show that low subglacial permeability should lead to filtering of the response of ice flow to tidal forcing. If this is true for Whillans Ice Stream, then the combination of the low till permeability suggested by our findings and the tidally modulated twice-daily stick-slip motion of the ice stream indicates its response to tides is not controlled by fluid connectivity through the grounding zone till.

\subsection{Estimating source size $\left(A_{0}\right)$}

Our preferred method of estimating source size is only possible when a portion of the survey area contains a known reflection interface. The interface need not be known exactly, as demonstrated by our retrieval of basal ice properties alongside estimating source size, provided the shape of the $R(\theta)$ response varies with changing properties along with the absolute level of reflectivity. Comparison with other methods used to estimate $A_{0}$ demonstrates the efficacy of the commonly employed multiple-bounce method (Fig. 5). $A_{0}$ estimated using the multiple-bounce method was, however, approximately twice that estimated using our known reflector method (Fig. 5). This difference can be reduced by a more thorough treatment of the path amplitude factor $\left(\gamma_{i}\right)$. For instance, applying the geometric loss estimated by Margrave (2003) results in a best-fitting gradient of 1.6. The remaining difference can be accounted for by varying $\alpha$ in our known reflectivity $A_{0}$ calculation, with an $\alpha=6.0 \mathrm{~km}^{-1}$ resulting in a $1: 1$ relationship between the multiple-bounce and known reflector methods, albeit with a linear intercept of approximately 100 . Instead of using path amplitude factors from Margrave (2003) and adjusting our $\alpha$ estimate, we have chosen the inverse pathlength approach of Eq. (2) and a published $\alpha$ estimate for clarity and to better enable repeatability. The discrepancy between the methods indicates that attenuation $(\alpha)$ and path amplitude factors $(\gamma)$ remain areas of uncertainty, overcome here by our use of a known reflector. In the absence of reliable $A_{0}$ estimates, other attributes of the amplitude reflection curve such as the angle of phase change (e.g. Anandakrishnan, 2003a) can be effective predictors of subglacial geology. Direct-path methods for $A_{0}$ estimation have been successfully employed elsewhere (Muto et al., 2019), and greatly simplify $R(\theta)$ recovery. Muto et al. (2019) presented data where the sources were buried at 40 $50 \mathrm{~m}$ depth, compared to our $27 \mathrm{~m}$, and their signal-to-noise ratios are high, as evident in their imaging of englacial seismic reflectivity. The poor correlation between our knownreflector and direct-path $A_{0}$ estimates (Fig. 4) shows that further investigation of direct-path methods is warranted. Both the direct-path methods we present would benefit from a greater offset distribution, and the direct pair method would 
benefit from a greater number of path combinations where $s_{2} / s_{1}=2$ than was available to us. Trace interpolation could also be used here as the direct arrival energy is unlikely to change rapidly. Also, the path effects $\left(\gamma_{\mathrm{d}, i}\right)$ experienced by the direct ray are likely to be inadequately captured by our approach due to the possibility of unaccounted for energy loss and more complex travel paths than those predicted within the firn.

Our Zoeppritz fitting methodology is skilled at recovering both $V_{\mathrm{p}}$ and $\rho$ as demonstrated in the floating portions of all lines where the recovered values are those expected for water (see Table 5 floating estimates). The methodology is less skilful at recovering $V_{\mathrm{s}}$, likely due to the weaker dependence of the shape of the $R(\theta)$ curve on $V_{\mathrm{s}}$ for the angles we observe. Using average source sizes and the known reflector method, we recover the near-zero $V_{\mathrm{s}}$ typical of water for 73 of the 112 floating shots in our survey. Estimating $V_{\mathrm{s}}$ along with $\rho$ allows the shear modulus to be estimated, which can be used to calculate the effective pressure in the till (Luthra et al., 2016). This provides a more direct link between seismic observations and till properties than is otherwise possible from estimates of normal incidence reflectivity $\left(R_{\mathrm{b}}\right)$ alone. An acquisition geometry that covered greater angles would improve our ability to estimate $V_{\mathrm{s}}$; however, limitations due to interference from direct arrivals would still exist. These limitations could be overcome by observing much greater offsets, where direct arrivals no longer interfere with the bed return, or surveying in regions of greater ice thickness. Using multiple charge sizes and configurations also highlights the importance of source configuration. Line 3, which consisted of the largest charges by weight $(0.85 \mathrm{~kg})$, resulted in the lowest $A_{0}$ estimates calculated from both the known reflector method and the multiple-bounce method. The charges for line 3 were made up of a stack of a single $0.4 \mathrm{~kg}$ charge and three narrower $0.15 \mathrm{~kg}$ charges. These narrower charges were likely less well coupled with the shot hole wall, and the longer linear configuration resulted in a less effective source. A shorter interval between shot loading and detonation may have also been a factor here as line 3 was shot within $1-2 \mathrm{~d}$ of loading.

\section{Conclusions}

Subglacial material beneath Whillans Ice Stream's grounding zone is relatively stiff, exhibiting $V_{\mathrm{s}} \approx 1100 \mathrm{~m} \mathrm{~s}^{-1}$ and Young's moduli of 3.2-6.2 GPa, making it more similar to a subglacial sticky spot than to deforming till. The transition from this stiff subglacial sediment to the ocean cavity is abrupt, occurring over distances of 500-1000 m. This seismically imaged transition differs from that imaged using RES, which detects both an abrupt transition and a gradual one at the embayment and promontory respectively (Christianson et al., 2016). Upstream of the grounding line we detect thin, apparently isolated, bodies of water. These findings are con- sistent with models that compact till within the grounding zone and those that isolate water upstream of the grounding zone, although we cannot detect whether the subglacial water is sourced from the ocean cavity or subglacially. Our comparison of methods used to determine source size $\left(A_{0}\right)$ shows that the commonly employed multiple-bounce method correlates well with the known reflector method available to us. However, our comparison also highlights that path effects $\left(\gamma_{i}\right)$ are incompletely modelled by the methods employed here and elsewhere. Our findings also reinforce the need for consistency in source placement, configuration, and time between burial and detonation. Overall our methods are skilled at retrieving basal properties at relatively high spatial resolution where the thickness of the subglacial material is sufficient to prevent thin film effects $(>\lambda / 4)$. Both $V_{\mathrm{p}}$ and $\rho$ are reliably retrieved, while $V_{\mathrm{s}}$ is recovered less consistently. While we are currently unable to accurately recover all seismic properties for what appear to be thin water layers, our methods do show promise here. These thin layers are pertinent for ice flow, and techniques such as full waveform inversion are likely to prove useful here. These methods, which invert not just for a single amplitude of the basal return but also for the full time series, have been successfully applied to other environments where thin layers with large contrasts in seismic properties have been investigated (e.g. Pecher et al., 1996).

Code and data availability. Data analysis and modelling used MATLAB $^{\circledR}$ and the CREWES MATLAB Toolbox (https://www. crewes.org/, Margrave, 2003). Seismic data processing and picking were performed using GLOBEClaritas (https://www.globeclaritas. com, Ravens, 1999). Seismic data are available at Scholarsphere (https://doi.org/10.26207/zx1s-9e98, Anandakrishnan, 2021).

Competing interests. The authors declare that they have no conflict of interest.

Acknowledgements. We are grateful to Rory Hart, Matthew Hill, and Benjamin Petersen for assistance in the field. Huw J. Horgan thanks Roger Clark for helpful correspondence early in this study. This study was funded by US National Science Foundation grants to the CReSIS (0852697) and WISSARD (0838764, 0838763) projects. Huw J. Horgan acknowledges funding from a Rutherford Discovery Fellowship and Project-1 of the New Zealand Antarctic Science Platform. The anonymous reviewer, Alex Brisbourne, and the editor Reinhard Drews are thanked for their comments.

Financial support. This research has been supported by the Marsden Fund (grant nos. RDF-VUW1602 and VUW1313), the National Science Foundation, Office of Polar Programs (grant nos. 0852697, 
0838764, and 0838763), and the New Zealand Antarctic Science Platform (Project 1, Antarctic Ice Dynamics).

Review statement. This paper was edited by Reinhard Drews and reviewed by Alex Brisbourne and one anonymous referee.

\section{References}

Aki, K. and Richards, P. G.: Quantitive Seismology. Theory and Methods, W. H. Freeman and Co., San Francisco, USA, 1980.

Anandakrishnan, S.: Dilatant till layer near the onset of streaming flow of Ice Stream C, West Antarctica, determined by AVO (amplitude vs offset) analysis, Ann. Glaciol., 36, 283-286, https://doi.org/10.3189/172756403781816329, 2003a.

Anandakrishnan, S.: Dilatant till layer near the onset of streaming flow of Ice Stream C, determined by AVO (Amplitude vs. Offset) analysis, Ann. Glaciol., 36, 283-287, 2003b.

Anandakrishnan, S.: Original Seismic Data from the Grounding Line of Whillans Ice Stream, ScholarSphere, https://doi.org/10.26207/zx1s-9e98, 2021.

Anandakrishnan, S., Voigt, D. E., Alley, R. B., and King, M. A.: Ice stream D flow speed is strongly modulated by the tide beneath the Ross Ice Shelf, Geophys. Res. Lett., 30, 1361, https://doi.org/10.1029/2002GL016329, 2003.

Beem, L. H., Tulaczyk, S. M., King, M. A., Bougamont, M., Fricker, H. A., and Christoffersen, P.: Variable deceleration of Whillans Ice Stream, West Antarctica, J. Geophys. Res.-Earth, 119, 212-224, https://doi.org/10.1002/2013jf002958, 2014.

Begeman, C. B., Tulaczyk, S. M., Marsh, O. J., Mikucki, J. A., Stanton, T. P., Hodson, T. O., Siegfried, M. R., Powell, R. D., Christianson, K., and King, M. A.: Ocean Stratification and Low Melt Rates at the Ross Ice Shelf Grounding Zone, J. Geophys. Res.Oceans, 123, 7438-7452, https://doi.org/10.1029/2018jc013987, 2018.

Bindschadler, R., Choi, H., Wichlacz, A., Bingham, R., Bohlander, J., Brunt, K., Corr, H., Drews, R., Fricker, H., Hall, M., Hindmarsh, R., Kohler, J., Padman, L., Rack, W., Rotschky, G., Urbini, S., Vornberger, P., and Young, N.: Getting around Antarctica: new high-resolution mappings of the grounded and freely-floating boundaries of the Antarctic ice sheet created for the International Polar Year, The Cryosphere, 5, 569-588, https://doi.org/10.5194/tc-5-569-2011, 2011.

Bindschadler, R. A., King, M. A., Alley, R. B., Anandakrishnan, S., and Padman, L.: Tidally Controlled Stick-Slip Discharge of a West Antarctic Ice Stream, Science, 301, 1087-1089, 2003.

Blankenship, D. D., Bentley, C. R., Rooney, S. T., and Alley, R. B.: Seismic Measurements Reveal a Saturated, Porous Layer Beneath an Active Antarctic Ice Stream, Nature, 322, 54-57, 1986.

Booth, A. D., Clark, R. A., Kulessa, B., Murray, T., Carter, J., Doyle, S., and Hubbard, A.: Thin-layer effects in glaciological seismic amplitude-versus-angle (AVA) analysis: implications for characterising a subglacial till unit, Russell Glacier, West Greenland, The Cryosphere, 6, 909-922, https://doi.org/10.5194/tc-6-9092012, 2012.

Brisbourne, A. M., Smith, A. M., Vaughan, D. G., King, E. C., Davies, D., Bingham, R. G., Smith, E. C., Nias, I. J., and Rosier,
S. H. R.: Bed conditions of Pine Island Glacier, West Antarctica, J. Geophys. Res.-Earth, 122, 419-433, 2017.

Brunt, K. M., Fricker, H. A., and Padman, L.: Analysis of ice plains of the Filchner-Ronne Ice Shelf, Antarctica, using ICESat laser altimetry, J. Glaciol., 57, 965-975, https://doi.org/10.3189/002214311798043753, 2011.

Carter, S. and Fricker, H. A.: The supply of subglacial meltwater to the grounding line of the Siple Coast, West Antarctica, Ann. Glaciol., 53, 267-280, 2012.

Christianson, K., Parizek, B. R., Alley, R. B., Horgan, H. J., Jacobel, R. W., Anandakrishnan, S., Keisling, B. A., Craig, B. D., and Muto, A.: Ice sheet grounding zone stabilization due to till compaction, Geophys. Res. Lett., 40, 5406-5411, 2013.

Christianson, K., Jacobel, R. W., Horgan, H. J., Alley, R. B., Anandakrishnan, S., Holland, D. M., and DallaSanta, K. J.: Basal conditions at the grounding zone of Whillans Ice Stream, West Antarctica, from ice-penetrating radar, J. Geophys. Res.-Earth, 121, 1954-1983, 2016.

Dawson, G. J. and Bamber, J. L.: Measuring the location and width of the Antarctic grounding zone using CryoSat-2, The Cryosphere, 14, 2071-2086, https://doi.org/10.5194/tc-14-20712020, 2020.

Erofeeva, S., Padman, L., and Howard, S. L.: Tide Model Driver (TMD) version 2.5, Toolbox for Matlab, Tech. Rep., available at: https://www.github.com/EarthAndSpaceResearch/ TMD_Matlab_Toolbox_v2.5, last access: 10 August 2020.

Fricker, H. A., Powell, R. D., Priscu, J. C., Tulaczyk, S., Anandakrishnan, S., Christner, B., Fisher, A. T., Holland, D. M., Horgan, H. J., Jacobel, R. W., Mikucki, J., Mitchell, A., Scherer, R., and Severinghaus, J. P.: Siple Coast subglacial aquatic environments: The Whillans Ice Stream Subglacial Access Research Drilling (WISSARD) project, chap. 12, AGU Monograph, American Geophysical Union, Washington, DC, USA, https://doi.org/10.1002/9781118670354.ch12, 2010.

Gudmundsson, G. H.: Tides and the flow of Rutford Ice Stream, West Antarctica, J. Geophys. Res., 112, F04007, https://doi.org/10.1029/2006jf000731, 2007.

Hamilton, E. L.: $V_{\mathrm{p}} / V_{\mathrm{s}}$ and Poisson's ratios in marine sediments and rocks, J. Acoust. Soc. Am., 66, 1093-1101, 1979.

Haran, T., Bohlander, J., Scambos, T., and Fahnestock, M.: MODIS mosaic of Antarctica (MOA) image map, NSIDC Digital media, Boulder, CO, USA, 2005.

Holdsworth, G.: Flexure of a floating ice tongue, J. Glaciol., 8, 385397, 1969.

Holdsworth, G.: Tidal interaction with ice shelves, Ann. Geophys., 33, 133-146, 1977.

Holland, C. and Anandakrishnan, S.: Subglacial seismic reflection strategies when source amplitude and medium attenuation are poorly known, J. Glaciol., 55, 931-937, 2009.

Horgan, H. J., Anandakrishnan, S., Alley, R. B., Burkett, P. G., and Peters, L. E.: Englacial seismic reflectivity - Imaging crystal orientation fabric in West Antarctica, J. Glaciol., 57, 639-650, 2011.

Horgan, H. J., Alley, R. B., Christianson, K., Jacobel, R. W., Anandakrishnan, S., Muto, A., Beem, L. H., and Siegfried, M. R.: Estuaries beneath ice sheets, Geology, 41, 1159-1162, https://doi.org/10.1130/G34654.1, 2013a.

Horgan, H. J., Christianson, K., Jacobel, R. W., Anandakrishnan, S., and Alley, R. B.: Sediment deposition at the modern grounding 
zone of Whillans Ice Stream, West Antarctica, Geophys. Res. Lett., 40, 3934-3939, 2013b.

Joughin, I., Abdalati, W., and Fahnestock, M.: Large fluctuations in speed on Greenland's Jakobshavn Isbræ glacier, Nature, 432, 608-610, 2004a.

Joughin, I., MacAyeal, D. R., and Tulaczyk, S.: Basal shear stress of the Ross ice streams from control method inversions, J. Geophys. Res.-Sol. Ea., 109, 1-20, https://doi.org/10.1029/2003jb002960, 2004b.

Kohnen, H.: The temperature dependence of seismic waves in ice, J. Glaciol., 13, 144-147, 1974.

Kohnen, H. and Bentley, C. R.: Seismic Refraction and Reflection measurements at "Byrd" Station, Antarctica, J. Glaciol., 12, 101$111,1973$.

Lipovsky, B. P. and Dunham, E. M.: Slow-slip events on the Whillans Ice Plain, Antarctica, described using rate-and-state friction as an ice stream sliding law, J. Geophys. Res.-Earth, 122, 973-1003, https://doi.org/10.1002/2016jf004183, 2017.

Luthra, T., Anandakrishnan, S., Winberry, J. P., Alley, R. B., and Holschuh, N.: Basal characteristics of the main sticky spot on the ice plain of Whillans Ice Stream, Antarctica, Earth Planet. Sc. Lett., 440, 12-19, https://doi.org/10.1016/j.epsl.2016.01.035, 2016.

MacGregor, J. A., Anandakrishnan, S., Catania, G. A., and Winebrenner, D. P.: The grounding zone of the Ross Ice Shelf, West Antarctica, from ice-penetrating radar, J. Glaciol., 57, 917-928, https://doi.org/10.3189/002214311798043780, 2011.

Margrave, G. F.: Numerical Methods of Exploration Seismology, The University of Calgary, Calgary, Canada, https://doi.org/10.1017/9781316756041, 2003.

Marsh, O. J., Rack, W., Floricioiu, D., Golledge, N. R., and Lawson, W.: Tidally induced velocity variations of the Beardmore Glacier, Antarctica, and their representation in satellite measurements of ice velocity, The Cryosphere, 7, 1375-1384, https://doi.org/10.5194/tc-7-1375-2013, 2013.

Minchew, B. M., Simons, M., Riel, B., and Milillo, P.: Tidally induced variations in vertical and horizontal motion on Rutford Ice Stream, West Antarctica, inferred from remotely sensed observations, J. Geophys. Res.-Earth, 122, 167-190, https://doi.org/10.1002/2016jf003971, 2017.

Muto, A., Anandakrishnan, S., Alley, R. B., Horgan, H. J., Parizek, B. R., Koellner, S., Christianson, K., and Holschuh, N.: Relating bed character and subglacial morphology using seismic data from Thwaites Glacier, West Antarctica, Earth Planet. Sci. Lett., 507, 199-206, 2019.

Pattyn, F., Perichon, L., Durand, G., Favier, L., Gagliardini, O., Hindmarsh, R. C. A., Zwinger, T., Albrecht, T., Cornford, S., Docquier, D., Fürst, J., Goldberg, D., Gudmundsson, G., Humbert, A., Hütten, M., Huybrechts, P., Jouvet, G., Kleiner, T., Larour, E., Martin, D., Morlighem, M., Payne, A., Pollard, D., Rückamp, M., Rybak, O., Seroussi, H., Thoma, M., and Wilkens, N.: Grounding-line migration in plan-view marine icesheet models: results of the ice2sea MISMIP3d intercomparison, J. Glaciol., 59, 410-422, 2013.

Pecher, I. A., Minshull, T. A., Singh, S. C., and von Huene, R.: Velocity structure of a bottom simulating reflector offshore Peru: Results from full waveform inversion, Earth Planet. Sc. Lett., 139, 459-469, https://doi.org/10.1016/0012-821X(95)00242-5, 1996.
Peters, L. E., Anandakrishnan, S., Holland, C. W., Horgan, H. J., Blankenship, D. D., and Voigt, D. E.: Seismic detection of a subglacial lake near the South Pole, Antarctica, Geophys. Res. Lett., 35, 1-5, 2008.

Powell, R. D., Dawber, M., McInnes, J. N., and Pyne, A.: Observations of the grounding-line area of a floating glacier terminus, Ann. Glaciol., 22, 217-223, 1996.

Pratt, M. J., Winberry, J. P., Wiens, D. A., Anandakrishnan, S., and Alley, R. B.: Seismic and geodetic evidence for groundingline control of Whillans Ice Stream stick-slip events, J. Geophys. Res.-Earth, 119, 333-348, 2014.

Ravens, J.: Globe Claritas, Seismic processing dictionary, Institute of gelogical and nuclear sciences, 99/12, 1999.

Robel, A. A., Tsai, V. C., Minchew, B., and Simons, M.: Tidal modulation of ice shelf buttressing stresses, Ann. Glaciol., 58, 12-20, https://doi.org/10.1017/aog.2017.22, 2017.

Rosier, S. H. R. and Gudmundsson, G. H.: Exploring mechanisms responsible for tidal modulation in flow of the Filchner-Ronne Ice Shelf, The Cryosphere, 14, 17-37, https://doi.org/10.5194/tc14-17-2020, 2020.

Rosier, S. H. R., Gudmundsson, G. H., and Green, J. A. M.: Temporal variations in the flow of a large Antarctic ice stream controlled by tidally induced changes in the subglacial water system, The Cryosphere, 9, 1649-1661, https://doi.org/10.5194/tc9-1649-2015, 2015.

Rosier, S. H. R., Marsh, O. J., Rack, W., Gudmundsson, G. H., Wild, C. T., and Ryan, M.: On the interpretation of ice-shelf flexure measurements, J. Glaciol., 63, 783-791, https://doi.org/10.1017/jog.2017.44, 2017.

Röthlisberger, H.: Seismic exploration in cold regions, Tech. Rep., Cold regions research and engineering lab, Hanover NH, 1972.

Sayag, R. and Worster, M. G.: Elastic response of a grounded ice sheet coupled to a floating ice shelf, Phys. Rev. E, 84, 036111, https://doi.org/10.1103/physreve.84.036111, 2011.

Sayag, R. and Worster, M. G.: Elastic dynamics and tidal migration of grounding lines modify subglacial lubrication and melting, Geophys. Res. Lett., 40, 5877-5881, https://doi.org/10.1002/2013g1057942, 2013.

Scherer, R. P., Powell, R. D., Coenen, J. J., Hodson, T. O., Puttkammer, R., and Tulaczyk, S. M.: Geological and paleontological results from the WISSARD (Whillans Ice Stream Subglacial Access Research Drilling) Project, AGU Fall Meeting Abstracts, 2015.

Schmeltz, M., Rignot, E., and MacAyeal, D.: Tidal flexure along ice sheet margins: comparison of InSAR with an elastic plate model, Ann. Glaciol., 34, 202-208, 2002.

Shearer, P. M.: Introduction to seismology, Cambridge University Press, New York, USA, 2009.

Smith, A. M.: Basal conditions on Rutford Ice Stream, West Antarctica, from seismic observations, J. Geophys. Res., 102, 543-552, 1997.

Smith, A. M.: Subglacial bed properties from normal-incidence seismic reflection data, J. Environ. Eng. Geophys., 12, 3-13, 2007.

Smith, A. M., Woodward, J., Ross, N., Bentley, M. J., Hodgson, D. A., Siegert, M. J., and King, E. C.: Evidence for the long-term sedimentary environment in an Antarctic subglacial lake, Earth Planet. Sc. Lett., 504, 139-151, https://doi.org/10.1016/j.epsl.2018.10.011, 2018. 
Sugiyama, S., Sawagaki, T., Fukuda, T., and Aoki, S.: Active water exchange and life near the grounding line of an Antarctic outlet glacier, Earth Planet. Sc. Lett., 399, 52-60, https://doi.org/10.1016/j.eps1.2014.05.001, 2014.

Tsai, V. C. and Gudmundsson, G. H.: An improved model for tidally modulated grounding-line migration, J. Glaciol., 61, 216-222, https://doi.org/10.3189/2015jog14j152, 2015.

van der Veen, C. J., Ahn, Y., Csatho, B. M., Mosley-Thompson, E., and Krabill, W. B.: Surface roughness over the northern half of the Greenland Ice Sheet from airborne laser altimetry, J. Geophys. Res., 114, F01001, https://doi.org/10.1029/2008jf001067, 2009.

Vaughan, D. G.: Tidal flexure at ice shelf margins, J. Geophys. Res., 100, 6213-6224, 1995.

Voigt, D. E., Peters, L. E., and Anandakrishnan, S.: "Georods": the development of a four-element geophone for improved seismic imaging of glaciers and ice sheets, Ann. Glaciol., 54, 142-148, https://doi.org/10.3189/2013AoG64A432, 2013.

Walker, R. T., Parizek, B. R., Alley, R. B., Anandakrishnan, S., Riverman, K. L., and Christinason, K.: Ice-shelf tidal flexure and subglacial pressure variations, Earth Planet. Sci. Lett., 361, 422428, 2013.
Walter, J. I., Brodsky, E. E., Tulaczyk, S., Schwartz, S. Y., and Pettersson, R.: Transient slip events from near-field seismic and geodetic data on a glacier fault, Whillans Ice Plain, West Antarctica, J. Geophys. Res., 116, F01021, https://doi.org/10.1029/2010JF001754, 2011.

Warburton, K. L. P., Hewitt, D. R., and Neufeld, J. A.: Tidal Grounding-Line Migration Modulated by Subglacial Hydrology, Geophys. Res. Lett., 47, e2020GL089088, https://doi.org/10.1029/2020gl089088, 2020.

Wild, C. T., Marsh, O. J., and Rack, W.: Viscosity and elasticity: a model intercomparison of ice-shelf bending in an Antarctic grounding zone, J. Glaciol., 63, 573-580, https://doi.org/10.1017/jog.2017.15, 2017.

Winberry, J. P., Anandakrishnan, S., Alley, R. B., Bindschadler, R. A., and King, M. A.: Basal mechanics of ice streams: Insights from the stick-slip motion of Whillans Ice Stream, West Antarctica, J. Geophys. Res., 114, 1-11, 2009.

Zechmann, J. M., Booth, A. D., Truffer, M., Gusmeroli, A., Amundson, J. M., and Larsen, C. F.: Active seismic studies in valley glacier settings: strategies and limitations, J. Glaciol., 64, 796$810,2018$. 